\title{
5 Anachronismus in Ovids „Metamorphosen“
}

Der Anachronismus als das erste konkret am Text zu diskutierende Phänomen ist heuristisch das unproblematischste: Der Erzähler macht mindestens zwei Aussagen oder lässt solche Aussagen machen, die epistemisch auf gleicher oder gleiches Wissen voraussetzender Ebene stehen und eine widersprüchliche zeitliche Implikation zum Ausdruck bringen. Ein markantes Beispiel hierfür ist Herakles, dessen göttlicher Körperanteil nach seinem Tod verstirnt wird (met. IX, 271f.), der dann aber zwei Bücher später und zudem recht eindeutig über seinen (menschlichen) Großvater als Alcides bezeichnet (met. XI, 213) nochmals als handelnde Figur auftaucht, um zusammen mit Telamon Troja zum ersten Mal zu erobern. ${ }^{1}$

Schon bei diesem Beispiel fällt auf, dass die beiden einander widersprechenden Informationen nicht aufeinander bezogen sind, sondern lediglich nacheinander geäußert werden. Folglich hat es den Anschein, als koexistierten deren Implikationen unabhängig voneinander und nebeneinander: Aus der anschaulichen Schilderung der Verbrennung und des Katasterismos geht hervor, dass Herakles tot ist, ${ }^{2}$ aus seinem späteren Wirken als diegetische Figur, dass er noch lebt. Dass aber der Alcides (met. XI, 213) jener zuletzt Tyrinthius (met. IX, 268) genannte Heros ist, bleibt - obschon die Verbindung vom Leser problemlos hergestellt wird -, gleichermaßen implizit wie die von der Erzählung bis dahin bestärkte Annahme, dass zwischen dem neunten und dem elften Buch die Zeit vorangeschritten ist und auch der Tod des Herakles schon in der ferneren Vergangenheit liegt. Notwendigerweise erweist sich eine dieser Prämissen - hier fraglos die letztere - als Fehlannahme und ein Rezipient ist wohl zum wiederholten Mal zur kritischen Revision der eigenen, offenbar naiven Erwartung gegenüber der Darstellung aufgefordert. ${ }^{3}$

Entscheidend für ein objektiveres Bild zu diesem Phänomen ist daher die Frage, wie die Erzählung eine solche Erwartung zuvor aufbaut und wie nachdrücklich diese dann durch die zusätzliche kontradiktorische Information als falsch erwiesen wird. Im Wesentlichen sind hierfür zwei Fälle zu unterscheiden, von denen der erste als eine erzählerische Gegenstrategie des poeta doctus zum eigenen Erzählen in oder mit der Zeit angesehen werden kann und der zweite als impliziter Anachronismus bzw. Aktualisierung zweiter Stufe, welche sich dadurch ergibt, dass die Kommunikationsoder Handlungssituation narrativ in einem spezifischen Kontext der diegetischen Welt verankert ist.

\footnotetext{
1 Vgl. dazu Wheeler 1999a, 135-139 und Kenney 2011, ad met. IX, 1-272 sowie Reed 2013, ad met. XI, $194-215$.

2 Die fiktive Authentizität des Ereignisses wird zusätzlich noch dadurch unterstrichen, dass Atlas, der das Himmelsgewölbe trägt, in jener typisch ovidischen Realistik das Gewicht des neu am Himmel hinzugekommenen Sternes spürt: sensit Atlas pondus (met. IX, 273). Vgl. Haupt/Korn ${ }^{5} 1966$, ad loc. 3 Zum ästhetischen Reiz eines solchen Getäuscht-Werdens s.u. Kap. 7.2.1.2.
} 


\subsection{Anachronismus als narrativer Selbstwiderspruch}

Um mit dem Erstgenannten zu beginnen, folgen alle hierzu zu zählenden Beispiele, die sich auf insgesamt sieben Gruppen konzentrieren lassen, dem bei Herakles erkennbaren Muster: Eine an sich überzeugende Behauptung des Erzählers erweist sich im Nachhinein als nur eingeschränkt gültig. Ausgehend von diesem Prinzip kann dahingehend ein Unterschied gesehen werden, ob sich der Anachronismus vornehmlich auf die Aitiologie eines Phänomens selbst bezieht oder ob davon das zeitliche Gerüst der Gesamterzählung betroffen ist.

\subsubsection{Ovids Gegen- bzw. Neudatierungen}

Ovids sonstiger Umgang mit kanonischen mythischen wie historischen Zeitangaben in den „Metamorphosen“ kann als eine „strategic uncertainty“4 bezeichnet werden, durch die die eigene, dem dichterischen Formwillen unterworfene Zeit profiliert wird. Im Umfeld zweier für eine Mythenchronologie sehr prominenter Stoffkomplexe sind hierfür auch Anachronismen von Bedeutung: Argonautenfahrt und trojanischer Krieg.

\subsubsection{Die Argo, das wirklich erste Schiff (met. VI, 721 und met. VIII, 302)}

Das Beispiel der Argo ist eine Besonderheit, weil es abgesehen von der Prominenz dieses Topos nicht nur eine einzige scheinbar unverfängliche Behauptung ist, die der Erzähler über die diegetische Realität vorbringt, sondern eine Vielzahl an Aussagen mitsamt einer bis in kleinste Details auserzählten Motivik, wogegen dann späterhin anderslautende Aussagen existieren. ${ }^{5}$

So wird Schifffahrt schon an einer frühen Stelle in der Erzählung, bei der Abfolge der Menschengeschlechter im ersten Buch, als ein Symptom der ,frevlerischen Habsucht' (amor sceleratus habendi - met. I, 131) des Eisernen Geschlechtes genannt:

vela dabat ventis (nec adhuc bene noverat illos)

navita, quaeque diu steterant in montibus altis

fluctibus ignotis exsultavere carinae; ${ }^{6}$

Bemerkenswert ist sowohl die „besondere stilistische Betonung“7 beim archaisierenden navita (133) als auch die Darstellung als ein sich erst kürzlich entwickelter

4 Feeney 1999, 27.

5 Für den in der vorliegenden Deutung nur vereinzelt herangezogenen literaturgeschichtlichen Kontext bei der Argo s. Jackson 1997 und Bär 2012.

6 Met. I, 132-134: ,Den Winden - noch kannte man jene nicht gut - setzte der Seemann die Segel und, was lange Zeit auf hohen Bergen gestanden war, hüpfte nun als Kiel auf unbekannten Wogen.

7 Bömer 1969, ad loc. 
Vorgang, der durch den Rückbezug auf die explizit noch nicht (nondum - met. I, 94) entwickelte Schifffahrt in der Goldenen Zeit (met. I, 94-96), vom Gegensatz aus „Früher“ und „Später“ und von der Unbekanntheit dieser neuen Realität, welche mit adhuc (132) lose zeitlich verankert wird, herausgestellt ist. Zwar ist mit dieser Beschreibung, wenn man sie als ein allgemeines Sittengemälde auffasst, ${ }^{8}$ nicht per se ausgeschlossen, dass die Argonautenfahrt als dessen erste konkrete Manifestation mitbezeichnet wird, doch rückt diese spätestens mit den weiteren Beispielen, von denen die ersten wenige hundert Verse später folgen, in den Hintergrund. ${ }^{9}$

Erzählerisch ist es nur konsequent, dass Ovid dann, weil diese Kulturtechnik schon in jener dekadenten Zeit entwickelt worden ist, einerseits die durch die Flut pervertierte Lebenswelt mit konkretem Schifffahrtsvokabular erzählt (cumba ... adunca, ducit remos, navigat, figitur ... ancora, curvae ... carinae - met. I, 293-298), andererseits Deukalion und Pyrrha die Rettung durch einen ,kleinen Kahn` (parva rate ebd. 319) ermöglicht wird. Das thematische Erfordernis bzw. Potenzial - die ganze Erde steht gerade unter Wasser - stimmt in seiner Darbietung somit mit den bislang zu dieser Welt gegebenen Charakteristika gut überein.

Gleichermaßen können dann die weiteren Nennungen von Schiffen durch den „Präzedenzfall“ in met. I, 132-134 als in der Diegese legitimiert angesehen werden. Ein Novum ist beim dionysischen Schiffswunder (met. III, 577-700), dass neben der Gier als eher pessimistischer Begründung für die Seefahrt ein allzu menschlicher, gut nachvollziehbarer Grund ergänzt wird. Akoites, in seinen Worten ein armer Fischersohn, der von seinem Vater ,nichts außer dem Gewässer' (nihil ... praeter aquas $590 \mathrm{f}$.) ererbt hat, erwähnt dies folgendermaßen:

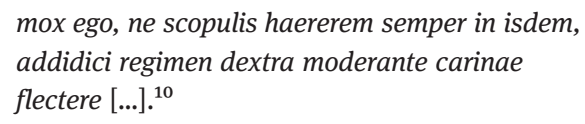

Seine Worte drücken sehr deutlich ein Bestreben aus, den engen Grenzen des Daseins entkommen zu wollen, und eine persönliche Weiterentwicklung, die er dem offenbar autodidaktisch erfolgten Zugewinn von Kenntnissen zu verdanken hat. Der Umstand, dass er denselben Vorgang mit drei gleichbedeutenden Wörtern (regimen, moderante, flectere - 593f.) und unter Einsatz sehr konkreter und darum redundant wirkender Objekte (dextra, regimen carinae - 593) ausdrückt, rückt die Aussage und zugleich ihren Sprecher in ein zweifelhaftes Licht. ${ }^{11}$ Das bestärkt Akoites auch im weiteren

8 Als solches reicht es auch bis zu Hesiod zurück. Vgl. dazu Barchiesi ${ }^{4} 2013$, ad met. I, 125-150.

9 Zur Verknüpfung des Zeitaltermythos mit dem Rest der „Metamorphosen“-Handlung s. ebd.

10 Met. III, 592-594: ,Bald habe ich, damit ich nicht immer auf denselben Felsen kleben bleibe, hinzugelernt, das Steuer des Kiels unter Führung meiner Rechten zu lenken.

11 Vgl. Bömer 1969, 588f. sowie ad met. III, 592-594. Für Bömer lässt sich dies entweder als „lapsus stili“ oder doch als - von ihm präferierte - beabsichtige Zurschaustellung der Falschheit und Weitschweifigkeit des Sprechers deuten. Dafür spricht auch, dass Pentheus am Ende von Akoites’ Bericht entgegnet, er habe dessen ,langen Ausschweifungen“ (longis ambagibus - 692) sein Gehör nun lange 
Verlauf seines Berichts, indem er spezifisches Nautik-Vokabular in derselben, lediglich der Veranschaulichung dienenden Weise einsetzt. ${ }^{12}$ Doch über die kontextuelle Bedeutung hinaus festigt dieses konkrete Denken und Handeln in Bezug auf Schiffe ein weiteres Mal den grundsätzlichen Eindruck, dass Seefahrt Teil der fiktiven Realität ist.

Überaus elaboriert ist das letzte affirmierende Beispiel, das zudem in einem quasihistorischen Zusammenhang erfolgt: ${ }^{13}$ Athen wird von einem Barbarenheer (barbara ... agmina - met. VI, 423) in Schrecken versetzt, das ,auf dem Meer herangefahren“ ist (subvecta ponto - 422). Aus der verhängnisvollen Entscheidung, den Thraker Tereus zur Hilfe zu rufen, ${ }^{14}$ entspinnt sich dann die Geschichte um Prokne, die diesem nach erfolgreichem Krieg aus Dank zur Frau gegeben wird und nach Thrakien folgt, und ihrer Schwester Philomela. Dass dann die Distanz zwischen Athen und Nordgriechenland mit Schiffen zurückgelegt wird, erscheint naheliegend. Als aber Tereus von Prokne gebeten wird, einen schwesterlichen Besuch egal in welcher Richtung zu ermöglichen, ist die genaue Art der Darbietung, wie Tereus unmittelbar im Anschluss daran buchstäblich statt Worten Taten folgen lässt, aufschlussreich:

iubet ille carinas

in freta deduci veloque et remige portus

[445]

Cecropios intrat Piraeaque litora tangit. ${ }^{15}$

Sein überstürztes Handeln spricht für sich und nimmt den weiteren Verlauf der Geschichte vorweg. ${ }^{16}$ Die Knappheit des Ausdrucks scheint sogar so groß zu sein, dass es im Falle von veloque remige (445) zu einer gekonnten Ambivalenz von eigentlicher und metaphorischer Bedeutung kommt. ${ }^{17}$ Knapp ist auch die Nennung des Ziels, das durch die Ausdifferenzierung als portus/ Cecropios (445f.) und Piraea litora (446) gerade noch auf der Ebene einer Analogie bleibt, aber die prototypische Vorstellung vom Piräus als Hafen Athens, den logischerweise auch ein Tereus avisiert, sowohl spielerisch zu evozieren als auch aus sich heraus aufzurufen vermag. ${ }^{18}$ Der Evidenz des Bezeichneten ist dies sehr zuträglich.

genug geschenkt. Auf Analogien innerhalb der Episode weisen zudem Barchiesi/Rosati 2007, ad met. III, 593, hin.

12 So in Vers 615f. die ,höchsten Rahen' (summas ... antemnas) oder das Schiffstau (rudens).

13 Zur Stelle selbst s.u. Kap. 6.2.

14 Dieser kommt wohl, obwohl es nicht expliziert wird, auch zu diesem Zweck schon auf dem Seeweg. 15 Met. VI, 444-446: ,Jener lässt die Schiffe ins Meer ziehen und betritt mit Segel und Ruder den kekropischen Hafen und landet an der piräischen Küste an.

16 Vgl. Anderson 1972 und Rosati ${ }^{2} 2013$, ad loc.

17 Denn dass er veloque et remige (445) in den Hafen fährt (intrat - 446), soll sicherlich nicht in erster Linie betont werden. Vgl. hierzu allgemein auch Bömer ${ }^{2} 2008$, ad loc.

18 Zur Unterscheidung Aktualisierung/Analogie s.u. Kap. 7.1.3.1a. Ein anderes Detail dieses Hafens kommt in der Erzählung bereits in met. II, 709 zur Geltung. S. dazu u. Kap. 6.3. 
Diese spielt für die Perspektive, aus der die Rückfahrt wahrgenommen wird, eine ebenso wichtige Rolle. Nachdem Tereus seinen Schwiegervater Pandion dazu gebracht hat, Philomela zu Besuch nach Thrakien mitreisen zu lassen, wird der neue Erzählabschnitt folgendermaßen eingeleitet:

ut semel imposita est pictae Philomela carinae

admotumque fretum remis tellusque repulsa est,

,vicimus!‘ exclamat ,mecum mea vota feruntur ${ }^{19}$

Durch das dreimalige Passiv im Nebensatz (imposita, admotum, repulsa - 511f.) als eine Art Retardation kann der diesen Augenblick wohl ungeduldig erwartende Tereus mit vicimus (513) umso markanter in Erscheinung treten und im doppelten Sinn mit der Sprache herausrücken. ${ }^{20}$ Auf das Subjekt Philomela hingegen, die wie eine Ware verladen $^{21}$ und auch inhaltlich auf ein Objekt (mea vota - 513) reduziert ist, das transportiert wird (feruntur - ebd.), scheinen die Vorgänge als äußere Eindrücke einzuwirken: Meer und Land sind heran- bzw. wegbewegt - Vorgänge wohlgemerkt, die sich ebenso auf sie selbst beziehen können; durch die Angabe der konkreten Ursache (remis - 512) wird der Vorgang kunstvoll mit der physischen Umgebung verknüpft. $^{22}$ Zusätzliche Lebendigkeit gewinnt die Erzählung noch durch die Aktualisierung, dass das Schiff bzw. dessen pars pro toto erwähnter Kiel bemalt ist (pictae ... carinae - 511). ${ }^{23}$ Dieser dekorative Aspekt, eine der wesentlichen Funktionen von Schiffsbemalung, ${ }^{24}$ bestärkt den Eindruck, dass die selbst als überaus schön dargestellte Philomela (451-454) auf dem überdies noch ausgeschmückten Schiff wie auf dem Präsentierteller ihrem Täter ausgeliefert wird, der im grellen Kontrast dazu als rücksichtsloser Verfechter seiner Leidenschaft charakterisiert ist (455-485).

Alle vier besprochenen Schiffsgeschichten im ersten, dritten und sechsten Buch zusammengenommen machen deutlich, dass eine bis in technische oder geographische Details ausdifferenzierte Seefahrt von Beginn an in der fiktiven Welt der „Me-

19 Met. VI, 511-513: ,Sobald Philomela in das bemalte Schiff gesetzt worden ist und das Meer von den Rudern heranbewegt und die Erde zurückgewiesen worden ist, ruft er: ,Sieg! Das Objekt meiner Wünsche wird mit mir selbst davongetragen'،

20 Die Fokalisierung dürfte daher schon im Nebensatz intern (Tereus) sein, d. h. die Beobachtung geht vom Schiff aus auf die Umwelt. Das erklärt auch, warum Ovid nicht die gegenteilige, hier ebenso gut geeignete Perspektive gewählt hat, dass jemand vom Ufer aus dem wegfahrenden Schiff hinterhersieht. Vgl. Anderson 1972, ad loc.

21 Die fachsprachliche Bedeutung im Schiffskontext ist bei imponere etabliert. Vgl. Bömer ${ }^{2} 2008$, ad loc.

22 Nicht allzu weit hergeholt ist es, hier an die Bildlichkeit impressionistischer Sprache zu denken (z.B. Rilkes „Römische Campagna“).

23 Zwar ist pictae wohl kaum mehr als eine Formel - auch jener in der Nautik so bewanderte Akoites verwendet sie (met. III, 639) -, doch verhilft sie dem Schiff, das zusammen mit pictae als Hyperbaton die auffallend passive Philomela umgibt, bereits an sich zu einer größeren Präsenz als fiktives Objekt. 24 S. Bömer 1958, ad fast. IV, 275: „Die Bemalung der Schiffe hatte vorwiegend drei Gründe: Schutzfarbe, Schmuck und apotropäische Absicht.“ 
tamorphosen“ relevant, ja fiktive Realität ist. Sei es die beinahe impressionistische Perspektive der auf dem Schiff sitzenden Philomela, der den Piräus ansteuernde Tereus, der übermäßig nautikaffine Akoites oder die Flutopfer - nicht zuletzt die anspruchsvolle Art und Weise ihrer erzählerischen Darbietung kann diese motivischthematische Verankerung unterstreichen. Die nachfolgenden Äußerungen am Ende des sechsten Buches zur Argonautenfahrt, an der mit Kalais und Zethes die Großneffen von Philomela teilnehmen, stehen folglich nicht in einem semantisch leeren Raum $^{25}$ und entspringen schon gar nicht der Vergesslichkeit des Dichters: ${ }^{26}$

ergo ubi concessit tempus puerile iuventae

vellera cum Minyis nitido radiantia villo

per mare non notum prima petiere carina. ${ }^{27}$

Dass die nicht namentlich genannte Argo mit prima carina (721) als das erste Schiff bezeichnet ist, fordert an diesem Punkt viel eher dazu auf, als Widerspruch erkannt zu werden - selbst wenn man carina auf den eigentlichen Sinn ,Kiel` festlegen wollte. ${ }^{28}$ Nicht nur steht die Information metrisch in einer bis hin zum Wortrhythmus identischen Stellung wie pictae ... carinae (met. VI, 511) und in prominenter Position am Versende des letzten Verses dieses Buches, ${ }^{29}$ sondern der Vorgang selbst ist übertrieben genau vorgestellt: Schon das tempus puerile iuventae (719) ist ein nur schwer zu übersetzender Pleonasmus, ebenso die vellera ... nitido radiantia villo (720), die unter Einsatz zusätzlicher Redefiguren ,in einem effektvollen Schlußakkord“30 dargeboten werden. So hilfreich und überzeugend diese Detailtreue in den Versen $719 \mathrm{f}$. aber ist sogar ein Zeitaspekt wird durch $u b i$ in Verbindung mit tempus noch einmal explizit ins Bewusstsein gerückt -, so offensichtlich unzutreffend ist sie dann im letzten Vers bei den beiden Attributen non notum und prima (721) angesichts der schon „früheren“ Seefahrt. Dass dann Iason als Teilnehmer der Kalydonischen Jagd noch als primaeque ratis molitor Iason (,und der Erbauer des ersten Schiffes Iason' - met. VIII, 302) beschrieben wird, bestärkt geradezu provokativ dieses Gegennarrativ.

Die Erzählung baut somit zunächst über ihre Plausibilität und den Rekurs auf bestens vertraute Begebenheiten einen Bedeutungszusammenhang auf, den sie durch

25 Das impliziert Tronchet 1998, 376 (Anm. 278), wonach die Distanz der Stellen - er berücksichtigt lediglich met. I, 134 und met. VI, 721 - die Wahrnehmbarkeit des Phänomens verringere.

26 So u.a. Haupt ${ }^{11} 1969$, ad met. VI, 721: „Ovid vergißt, daß er unmittelbar vorher (v. 511) von der Seefahrt des Tereus erzählt hat.“

27 Met.VI, 719-721: ,Sobald also das kindliche Alter es der Jugend gestattet hatte, strebten sie mit den Minyern nach dem von strahlenden Zotten funkelnden Fließ über das nicht bekannte Meer auf dem ersten Schiff.

28 Dieses lenkt bekanntlich schon Akoites' moderierende Hand in met. III, 593. Zur philologischen Tradition des Topos von der Argo als erstem Schiff s. Bömer ${ }^{2} 2008$, ad met. 721 und Bär 2012.

29 Das Schiff wird somit auch metapoetisch auf die Reise geschickt. Vgl. Rosati ${ }^{2} 2013$, ad met. VI, 720 f. 30 Bömer ${ }^{2} 2008$, ad met. VI, 720. 
ihre ostentativ harmlose Fortführung letztlich wieder problematisiert und ironisiert: ${ }^{31}$ Sie lässt ihren eigenen Erzähl- und Wahrheitsmodus, verstärkt durch die Schlussstellung des Verses im Buch, sozusagen ins Leere laufen. ${ }^{32}$ Ein solcher Formwille bei einem noch dazu so prominenten Motiv als Anachronismus ist daher mitnichten auf das fehlende Interesse Ovids für „diese Einzelheiten“ zurückzuführen. ${ }^{33}$

Im Gegenteil ist der Mythos so konsequent und so pointiert zu Ende erzählt, dass er sich durch seine immanente Widersprüchlichkeit zwangsläufig selbst widerspricht. ${ }^{34}$ Auf diese Weise bestätigt sich auch die Souveränität des eigenen fiktionalen Erzähl-Anspruches, diese Inkonsistenzen - anders als bei Faktualität - gar nicht erst zu harmonisieren; ${ }^{35}$ vielmehr können sie so überzeugend und mit so viel Witz inszeniert werden, dass sich ein Rezipient, der sich von dieser so attraktiven Schilderung trotzdem immer wieder aufs Neue hinreißen lässt, mit gleicher Regelmäßigkeit über seine credulitas wundern darf. ${ }^{36}$

\subsubsection{Die Helden „vor“ Troja}

Während bei der Argo die mytheninterne Unordnung nach außen hin sichtbar wird, scheint das plötzliche Wiederauftauchen des Herakles im elften Buch dem genau entgegengesetzten Zweck, dem Konsolidieren einer Zeitordnung, zu dienen. ${ }^{37}$ Nach den zeitlich eher unspezifischen Geschichten im weiteren Verlauf von Buch IX, die nach dem Tod des Herakles erzählt werden, nach dem fast das ganze zehnte Buch einnehmenden Orpheus-Gesang und nach den hauptsächlich über ihre Lokalisation in der nördlichen Ägäis verknüpften Mythen zu Beginn des elften Buches bietet sich mit der ersten Eroberung Trojas durch Herakles und Telamon ein sowohl mythhistorischer als auch genealogischer Fixpunkt. Hiervon kann die auf den trojanischen Krieg zustrebende Erzählung ihren Ausgang nehmen und frühere Ereignisse systematisieren.

31 So auch Tronchet 1998, 376.

32 Dass dies nicht der einzige Fall in den „Metamorphosen“ für eine solche Leser-Täuschung ist, sei mit Verweis auf weitere prominente Fälle nicht vergessen $\mathrm{zu}$ betonen (s.u. Kap. 6.4.3 und 7.1.3.1b). 33 Vgl. Bömer 22008, ad met. VI, 721. Dagegen ist bei Bär 2012, 214, in Bezug auf den gleichermaßen in den „Tristien“ zu findenden Widerspruch (Ov. trist. III, 9), im Zuge dessen auch auf die „Metamorphosen“ verwiesen wird, von einem „Vorführen“ die Rede.

34 Die Ähnlichkeit zu Euripides’ Mythen-Konzeption und -behandlung wird an dieser Stelle gut erkennbar. S. auch u. Kap. 7.2.2.1.

35 Vgl. Tronchet 1998, 376.

36 Um genau diese Form des urbanen Humors geht es nicht nur in jener „Amores“-Stelle (s. o. Kap. 3.1.2), sondern in den „Metamorphosen“ überhaupt (s. dazu von Albrecht 1963 und von Albrecht 2003, 162f.). Des Weiteren zum Aspekt der urbanitas aus ästhetischer Sicht s.u. Kap. 7.2.1.2a.

37 Vgl. dazu Wheeler 1999a, 138, der die nachfolgenden Anachronismen - die Figur Nestors ausgenommen - plausibel vor diesem Hintergrund deutet. 


\section{a) Herakles (met. IX, 271-273) und seine Pfeile (met. IX, 231f.)}

Eher unscheinbar und eine notwendige Begleiterscheinung zum zu neuem Leben gelangten Herakles ist der Anachronismus bei der Übergabe der Waffen an Philoktet:

arcum pharetramque capacem

regnaque visuras iterum Troiana sagittas ${ }^{38}$

Die Bedeutung von iterum (232) setzt ebenso wie der Umstand, dass Herakles kurz vor seinem Lebensende steht, voraus, dass sein Feldzug zu diesem Zeitpunkt abgeschlossen sein und auch die Gründung Trojas schon stattgefunden haben muss. ${ }^{39} \mathrm{Im}$ Kleinen wird durch das Attribut der Pfeile also das vorweggenommen, was in der Person des Herakles im Großen passiert.

\section{b) Peleus, der Vater Achills (met. VIII, 309)}

Ein dritter ähnlicher, gleichfalls nur an einem Detail erkennbarer Anachronismus ergibt sich aus der Nennung von Herakles' Begleiter Telamon. Weil dieser bei der ersten Eroberung Trojas mit der Erbeutung von Hesione nicht ehrlos (sine honore met. XI, 216) von dannen ziehen kann, bietet sich die Gelegenheit, ihn seinem Bruder Peleus beizugesellen, der sich schon im Besitz einer Frau weiß. ${ }^{40}$ Was folgt, ist eine Rückblende dazu, wie sich Peleus dieser Ehefrau (Thetis) bemächtigt hat, an deren Ende er in einer präsentischen Handlung Thetis mit dem ,ungeheuren Achilles füllt‘ (ingentique implet Achille - met. XI, 265). ${ }^{41}$ Dieser lebhafte Hintergrundbericht bringt wiederum ein Ereignis in seine zeitliche Ordnung, das an einer früheren Stelle bereits als ein Resultat angeführt worden ist: der in Antonomasie genannte magni creator Achillis (met. VIII, 309) bei der Jagd auf den Kalydonischen Eber.

Die Zuschreibung des extradiegetischen Erzählers, die ähnlich dem Attribut der herakleischen Pfeile oder dem der bemalten Schiffe prinzipiell eher traditionelle und deshalb zeitlose Eigenschaften vorbringt, erscheint durch den an späterer Stelle auserzählten Sachverhalt rückwirkend als eine verfrühte Aussage: Sie hatte „damals“ offenbar nichts mit der diegetischen Realität zu tun und konnte auch nicht ihrer tatsächlichen Beschreibung dienen. ${ }^{42}$

38 Met. IX, 231 f.: ,den Bogen und den vielfassenden Köcher und die Pfeile, die das trojanische Reich noch ein zweites Mal sehen sollten.

39 Zur intratextuellen Rekurrenz auf diese Waffen an späterer Stelle s. Wheeler 1999a, $137 \mathrm{f}$.

40 Die Verknüpfung zwischen beiden Brüdern erfolgt immerhin kausal über ein - sicherlich nicht sonderlich starkes - nam (met. XI, 217). Vgl. Bömer 22016, ad loc. Anders als es bei Wheeler 1999a, 137, lautet, kann ein zeitlicher Zusammenhang von Telamons Eroberung von Troja und seiner Teilnahme an der Argonautenfahrt aus den später erfolgenden Aussagen des fiktiven Aias allerdings nicht behauptet werden (met. XIII, 23f.).

41 Vgl. Reed 2013, ad loc. Der Gebrauch von implere dürfte im Lateinischen gleichermaßen ungewöhnlich für Menschen sein wie im Deutschen.

42 S. dazu besonders die Überlegungen in Kap. 6.2.1.2. 
Diese Diskrepanz zwischen Erzählung und Erzähltem verhält sich analog zu der grundsätzlich zu beobachtenden Ironisierung von Peleus' Heldenhaftigkeit, um die es wie bei den anderen Jagdteilnehmern schlecht bestellt zu sein scheint. ${ }^{43}$ Die Charakterisierung über die Zeugung Achills, die, wie der Leser in met. XI, 229-262 noch erfahren wird, gleichfalls eher unrühmlich vonstattengeht, ist damit bereits zu einem Zeitpunkt ihres Glanzes beraubt, noch ehe dieser in der diegetischen Realität sozusagen offiziell der creator seines Sohnes ist (ab met. XI, 265): Dieses vom Anachronismus schon getäuschte, aber mithilfe des nachgereichten Berichts für die PeleusFigur wiedergewonnene Leservertrauen wird dann mit der Schlusspointe ein letztes Mal herausgefordert:

felix et nato, felix et coniuge Peleus, et cui, si demas iugulati crimina Phoci omnia contigerant. ${ }^{44}$

Der doppelte Makarismos in Vers 266 scheint zunächst eine festliche, ganz den eben erfolgten Ereignissen gemäße Stimmung einzuleiten. Stünde da nicht ein Brudermord im Raum, dargestellt in einer prätentiös harmlosen Einschränkung, das Familienglück wäre perfekt.

\section{c) Nestor und das Alter (met. XII, 186-188)}

Ähnlich fragil ist auch Nestors Heldentum und -glück. Dieser weiß seine beinahe verhinderte Teilnahme am trojanischen Krieg durch ein wahres Kunststück bei der Jagd auf den Kalydonischen Eber gerade noch sicherzustellen:

forsitan et Pylius citra Troiana perisset

tempora, sed sumpto posita conamine ab hasta

arboris insiluit, quae stabat proxima, ramis

despexitque loco tutus quem fugerat hostem..$^{45}$

Mit einem „Ausdruck und Wortgefüge [...] so ungewöhnlich wie der geschilderte Vorgang“ ${ }^{46}$ wird Nestor nicht nur handlungsintern aus dem Geschehen katapultiert und in eine auktoriale Betrachter-Position gebracht, sondern auch metapoetisch

43 Vgl. Davis 1983, 111-119 und Tsitsiou-Chelidoni 2003, 223 (Anm. 631).

44 Met. XI, 266-268: ,Peleus, sowohl vom Glück gesegnet durch den Sohn als auch vom Glück gesegnet durch die Frau, und einer, dem, wenn man den Vorwurf des getöteten Phokos ausnehmen könnte, alles gelungen wäre.

45 Met. VIII, 365-368: ,Womöglich auch wäre der Pylier vor der trojanischen Zeit zugrunde gegangen, aber er sprang, nachdem er sich von der aufgesetzten Lanze Unterstützung verschafft hatte, ins Geäst eines nächststehenden Baumes und blickte vom Ort geschützt auf den Feind hinab, vor dem er geflohen war.'

46 Bömer 1977, ad loc. 
wieder aus einer Umgebung entfernt, wo er nach der Vulgata des Mythos nicht vorkommt. ${ }^{47}$ Vor dem Hintergrund all der Äußerungen, mit denen Nestor sowohl bei Homer als auch später in den „Metamorphosen“ seine mit jugendlicher Kraft verübten Großtaten auszumalen pflegt, könnte die Kluft größer nicht sein zu seinem tatsächlichen Handeln. ${ }^{48}$ Der zuvor als primis etiamnum Nestor in annis (,der jetzt noch in den ersten Jahren stehende Nestor ‘ - met. VIII, 313) eingeführte Held wird für seine spätere Rolle sozusagen noch aufgespart, aus der heraus er später dann auf seine ganz eigene Weise auf die früheren Leistungen zurückblicken kann. ${ }^{49}$

Mit der expliziten Zeitangabe citra Troiana ... tempora (365f.), in der ironischerweise die Möglichkeit eingeräumt ist, ${ }^{50}$ dass Nestor diese Zeit gar nicht hätte erleben können, werden er und seine Mitstreiter sowie das fiktive Jagdgeschehen in einem eindeutigen zeitlichen Raster verortet. Wenn Nestor dann in einer Kampfpause vor Troja retrospektiv über die Taten des Kaineus erzählt (met. XII, 182-535), der auch an der Eberjagd teilnimmt und wie Nestor (etiamnum) mit einem Zeitadverb als iam non femina (305) charakterisiert und auf einen spezifischen Entwicklungsstand hin festgelegt wird, ${ }^{51}$ bestärkt das gleichermaßen die diegetische Zeitordnung. ${ }^{52}$ Außerdem erweist sich der spätere intradiegetische Erzähler Nestor umso mehr als unglaubwürdig, wenn er für seine eigene Altersangabe, mit der er im zwölften Buch seine Autorität als Erzähler unterstreichen möchte, so sehr übertreibt, dass er sich dabei einen groben Anachronismus leistet:

ac si quem potuit spatiosa senectus

spectatorem operum multorum reddere, vixi

annos bis centum; nunc tertia vivitur aetas. ${ }^{53}$

47 Dies geschieht aber nicht durch „die Kraft seines Leibes“ (Tsitsiou-Chelidoni 2003, 223) - dann hätte er es auch ohne Hilfsmittel schaffen und zudem vor dem Eber nicht fliehen müssen -, sondern weil er im Gegensatz zum vorher getöteten Enaisimos flinker (und wohl auch furchtsamer) war. Vgl. Kenney 2011, ad loc. Erwähnenswert mag noch sein, dass in der „Ilias“ als die einzige Waffe Nestors der Speer genannt wird. Vgl. Watkins 1983, $136 \mathrm{f}$.

48 Vgl. Davis 1983, $117 \mathrm{f}$. und Watkins 1983, 137.

49 Dass Nestor in den „Metamorphosen“ ein Prahler ist, wird demnach hier schon motivisch angelegt. Vgl. Tsitsiou-Chelidoni 2003, 224 und Papaioannou 2007, 94.

50 So nähert laut Bömer 1977, ad loc, auch das auffällige Modaladverb (forsitan - 365) „den Irrealis dem Potentialis“ an, wodurch die Aussage stärker nach ihrer Möglichkeit statt ihrer Unmöglichkeit hin erscheint. Als erzählerischen Scherz deutet auch Kenney 2011, ad loc., die Erwähnung Nestors. Diese „Beinahe-Episode“ aber allein mit „einer momentanen Aufmerksamkeits- und Spannungssteigerung“ zu erklären, so Nesselrath 1992, 85 und mit identischer Festlegung bzw. Auslassung Nesselrath 2019, 590, wird der Komplexität von Ovids Nestor-Figur nicht gerecht.

$51 \mathrm{Zu}$ diesen Adverbien bei Epitheta s.u. S. 178f., Anm. 49.

52 An diesem Punkt knüpfen schließlich im elften Buch die mit dem Wiederauftauchen des Herakles einhergehenden Anachronismen an. Vgl. Tsitsiou-Chelidoni 2003, 225.

53 Met. XII, 186 - 188: , und wenn das langwierige Greisenalter einen zu einem Beobachter vieler Werke machen konnte: Ich habe 200 Jahre gelebt; nun wird das dritte Zeitalter gelebt.‘ 


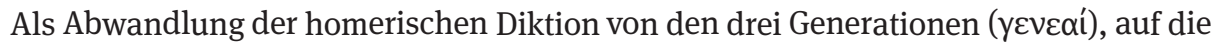
Nestor blicken kann, durch den doppelten Sinn von aetas (,Menschenalter ${ }^{6}$ und ,Zeitalter'), lässt Ovid seinen Helden aus einem Wissen schöpfen, das über die wenig rühmlichen Ereignisse in Kalydon hinausreicht, sodass sein Reden von den großen alten Zeiten noch aufrechterhalten werden kann. ${ }^{54}$ Der übergeordnete Primärerzähler widerlegt ihn aber durch die explizite Altersangabe primis etiamnum ... annis (met. VIII, 313), sodass seine Rede sich als genau das entpuppt, was sie ist: Jägerlatein im wahrsten Sinne des Wortes. ${ }^{55}$

Während aber bei Herakles, seinen Pfeilen und Peleus als Vater Achills die früher dargebrachte Behauptung durch die spätere neu qualifiziert wird und der zeitlichen Verortung der Erzählung dient, ist dies bei Nestors Anachronismus umgekehrt, da sich dort die spätere, aus dem Mund der Figur selbst stammende Aussage in ihrer vollen Tragweite durch die frühere, zeitlich klarer qualifizierende Angabe erschließt.

\subsubsection{Antizipierend-antizipierte Aitiologie}

Das im Kern schon bei Peleus und den Waffen des Herakles beobachtbare Muster, dass der Erzähler einem Objekt eine Eigenschaft zuschreibt, deren Zustandekommen er an späterer Stelle selbst noch berichten wird, kennzeichnet auch die nachfolgenden Beispiele.

\subsubsection{Phaethon und seine Äthiopen (met. I, 778f.)}

Dem ersten Anachronismus in den „Metamorphosen“ könnte, weil er einen der illustrativsten Fälle darstellt, eine gewisse Symbolfunktion zugesprochen werden. Phaethon, der Nachforschungen zu seinem wirklichen Vater anstellen möchte und deshalb von seiner Mutter zu Sol persönlich geschickt wird, macht sich folgendermaßen auf den Weg:

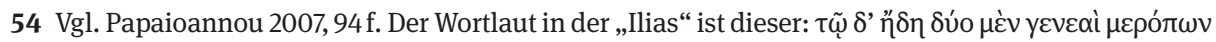

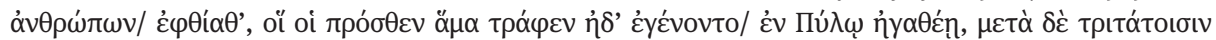

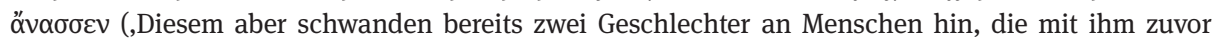
aufgezogen und geboren wurden im hochheiligen Pylos, unter den Dritten aber führte er nun seine Herrschaft.' - Hom. Il. I, 250-252).

55 Wie an späterer Stelle noch gezeigt wird, ist die unklare zeitliche Verortung von Nestors Vater Neleus ein weiterer Anachronismus, sodass die sonst so verlässliche Genealogie hier in den „Metamorphosen“ keine zufriedenstellende Ergänzung zu Nestors eigenem Alter liefert. S.u. Kap. 6.2.1.

Erwähnenswert ist es darüber hinaus, dass in der Jupiter-Prophezeiung am Ende der „Metamorphosen“ für das Leben des Augustus der Wunsch geäußert wird, es möge Pylios ... annos (,pylische Jahre، - met. XV, 838) erreichen. Angesichts der Unsicherheit über Nestors ,Jahre' kann in diesem Wunsch, der paradoxerweise auch noch als Schicksalsspruch in Stahl gemeißelt ist (s.u. Kap. 7.3.2.1b,k), ein subversiver Unterton angelegt sein. S. dazu (einschließlich der Konjektur bei Pylios) Hardie 2015, ad met. XV, 838. 
emicat extemplo laetus post talia matris

dicta suae Phaethon et concipit aethera mente

Aethiopasque suos positosque sub ignibus Indos

sidereis transit patriosque adit impiger ortus. ${ }^{56}$

Auffallend ist dabei zunächst, wie sehr die physikalische Welt, die Phaethon durchquert, mit ihrer mythologischen Überformung verschwimmt und letztlich am Zielpunkt der Bewegung, den patrios ... ortus (779), in einem einzigen Begriff aufgelöst wird: Sowohl der für die Phaethon-Geschichte notwendige Anthropomorphismus des Sonnengottes als auch das im Osten aufgehende Naturphänomen sind darin eingeschlossen. ${ }^{57}$ Die anderen Attribute scheinen hingegen wegen ihrer Plausibilität rein affirmativ zu sein: Das eine, suos (778), ist damit zu erklären, dass es sowohl Phaethons Nationalität als auch implizit den Startpunkt seines Weges anzeigt; das andere, ignibus sidereis (778f.), ist zwar in dieser Kombination ein unvermittelt starker Ausdruck, bereitet in der Junktur jedoch als Metapher für ,Sonnenstrahlen' keine Verständnisprobleme. ${ }^{58}$ Die ignes, zusammen mit dem in der eigentlichen Bedeutung bei Flammen typischen emicare (,hervorblitzen'), dürften aber bereits eine recht gute Vorahnung der kommenden Ereignisse geben; ${ }^{59}$ und in der auffallenden Häufung von ae- und $a$-Lauten im Umfeld von Phaethon, besonders bei aethera und Aethiopas, könnte auch eine kausale Verknüpfung dieser Objekte spielerisch antizipiert sein. ${ }^{60}$

Als dann das Unheil seinen Lauf genommen, Phaethon die Kontrolle über den Sonnenwagen verloren und die Welt in Brand gesetzt hat, kehrt die Erzählung nach einem ersten Katalog über die davon betroffenen Berge (met. II, 216-226) wieder auf eine allgemeine Ebene zurück und wird mit tum vero (met. II, 227) im diegetischen Jetzt verankert: Der zuvor ohnmächtig gewordene Phaethon ${ }^{61}$ erblickt nun den brennenden Erdkreis (orbem/ aspicit accensum - $227 \mathrm{f}$.), wobei manche Auswirkungen der Hitze noch mit weiteren Erfahrungen regelrecht nachempfindbar gemacht wer-

56 Met. I, 776-779.: ,Unverzüglich eilt Phaethon hinfort, glücklich nach derlei Worten seiner Mutter, und nimmt in sich gedanklich den Äther auf und schreitet an seinen Äthiopen und an den unter den Feuerstrahlen des Gestirns angesiedelten Indern vorbei und tritt eilends an den Aufgangsort seines Vaters heran.

57 Vgl. Feldherr 2016, 35. Zudem ist ortus (779), wie Barchiesi '2013, ad loc, anmerkt, ein metapoetisches Signal am Buchende.

58 Vgl. Bömer 1969, ad loc. In einer „Aeneis“-Stelle ist außerdem von einem Aethiopum locus die Rede, wo Atlas den Himmelspol trägt, der stellis ardentibus aptum (,geeignet für lodernde Sterne` - Aen. IV, 481f.) sei. Dies könnte als Vorbild für Ovids Metaphorik gelten. Vgl. Michalopoulos 2001, 21.

59 Vgl. Barchiesi ${ }^{4} 2013$, ad met. I, 776-779.

60 Vgl. Michalopoulos 2001, 21. Zu ergänzen ist noch, dass aether und Aethi-opes auf dasselbe Grundwort ä́ $\theta \varepsilon ı v$ (,brennen') zurückgehen. Unzutreffend aber ist die Etymologie, die Michalopoulos zu Phaethon anführt (als Kompositum von póos (,Licht') und aí $\theta \varepsilon ı v)$ ), ebenso dessen Gleichsetzung von Phaethon - als wäre das ae hier Diphthong - mit aether und Aethiops: Laut Frisk ist $\varphi \alpha \varepsilon \dot{\varepsilon} \theta \omega \mathrm{v}$ das um ein $\theta$ erweiterte Partizip zu einem thematischen Aorist $\varphi \alpha$ c (,leuchtete auf').

61 So heißt es in met. II, 200: mentis inops gelida formidine lora remisit (,von eiskalter Furcht ohnmächtig lässt er die Zügel erschlaffen'). 
den. ${ }^{62}$ Die hohe Evidenz des diegetischen Geschehens, die nicht zuletzt dem Umstand $\mathrm{zu}$ verdanken ist, dass es von einer diegetischen Figur als etwas Gegenwärtiges beobachtet wird, erweist sich in seiner Vermittlung durch den Erzähler unmittelbar im Anschluss aber als inhomogen oder ironisiert. Am Ende der Passage heißt es nämlich:

et neque iam cineres eiectatamque favillam

ferre potest calidoque involvitur undique fumo

quoque eat aut ubi sit picea caligine tectus

nescit et arbitrio volucrum raptatur equorum. ${ }^{63}$

Phaethon weiß buchstäblich nicht, wo er ist (ubi sit - 233), weil er von einer picea caligine (ebd.) eingehüllt ist. Für das zuvor erwähnte aspicit (228) liegt daher die Vermutung nahe, dass die damit verbalisierte Handlung trotz der internen Fokalisierung gar nicht intern fokalisiert ist, also ausschließlich der Perspektive des extradiegetischen Erzählers entspricht. ${ }^{64} \mathrm{Zu}$ fragen, inwiefern die anderen Sinneseindrücke der diegetischen Wirklichkeit entsprechen, d. h. ob sich Phaethon in seiner Lage ausgerechnet mit dem Glühen seines Wagens beschäftigt hat, mag in letzter Konsequenz spitzfindig sein; entscheidend ist aber, dass durch den Gegensatz von aspicit und caligine tectus die Diskrepanz zwischen Erzählung und erzählter Welt erkennbar wird. Anstelle eines objektiven oder faktualen Erzählers, der die Welt so abbildet, wie sie vermeintlich war, gibt sich auch hier der fiktional ausgestaltende, womöglich sogar ein wenig übertreibende ${ }^{65}$ Erzähler zu erkennen, der sich mit der Zeitangabe (tum vero - 227) und der Figuren-Perspektive sogar eben diesen Schein von Faktualität geben möchte.

Einer solchen Konsolidierung der Erzähler-Glaubwürdigkeit ist es auch förderlich, dass in den Versen 231f. mit der glühenden Asche und dem heißen Rauch, die als physikalische Erscheinung von außen auf Phaethon einwirken, bereits motivisch der Grund für die nachfolgende Aitiologie bereitet wird:

sanguine tum credunt in corpora summa vocato

Aethiopum populos nigrum traxisse colorem; ${ }^{66}$

62 Bei nec tantos sustinet austus (,und er erträgt die so große Hitze nicht ${ }^{\text {- }}$ 228), ferventesque auras ... trahit (,er atmet schwelende Lüfte، - 229f.), currusque suos candescere sentit (,und er fühlt seinen Wagen erglühen' - 230). Vgl. Bömer 1969, ad loc.

63 Met. II, 231-234.: ,Und nicht mehr kann er die Mengen an aufgeworfener Asche und Funken ertragen und er wird von allen Seiten von heißem Rauch eingehüllt und wo er hinfährt, und wo er ist, weiß er, bedeckt von pechschwarzer Finsternis, nicht und wird nach der Willkür der eilenden Pferde fortgerissen.

64 Obwohl bei einem in der Luft schwebenden Phaethon die realistische Möglichkeit dafür sogar gegeben wäre, erfolgt die Panorama-Ansicht sozusagen über seinen Kopf hinweg, aber nicht aus seinem Kopf heraus.

65 Vgl. Bernbeck 1967, $106 \mathrm{f}$.

66 Met. II, $235 \mathrm{f} .:$,Man glaubt, dass damals, weil das Blut an die Oberfläche ihrer Körper gereizt worden sei, die Völker der Äthiopen die schwarze Farbe angenommen hätten. 
Denn durch die vorherige Explikation der Umweltfaktoren, deren Effekt an Phaethon gerade gewissermaßen hautnah vorgeführt wurde, braucht die mit „physiologischer Präzision “67 dargebotene Erklärung für die dunkle Hautfarbe die äußere Ursache nicht noch einmal zu benennen. Mit einem zweiten tum (235) wird erneut auf die - aus dieser Sicht vergangene - diegetische Gegenwart hingewiesen, wobei der Erzähler mit credunt nun explizit die Distanz zum beschriebenen Vorgang anzeigt. Das ist nicht nur aus dem Grund erstaunlich, weil Ovid ausgerechnet bei einer Deutung in Bezug auf eine reale Erscheinung - im Gegensatz zu Phaethons Sinneseindrücken in den Versen 228-234 oder den ebenso ,damals' (ein drittes tum folgt direkt in 237) weinenden Nymphen (238f.) - die Verantwortung von sich weist. Hinzu kommt, dass sich durch diese Aitiologie eine zusätzliche, überaus ansprechende Querverbindung zur ersten Nennung von Phaethons Landsleuten herstellen lässt. ${ }^{68}$

Ovid gibt in der zweiten Stelle mit nigrum traxisse colorem (236) einen etymolo-

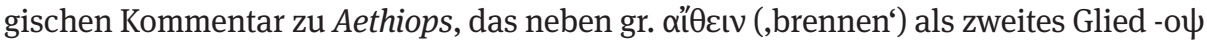
enthält, welches wie das Nomen ő $\psi$ ıৎ ein ,Sehen' sowie ,Gesicht, Anblick, Erscheinung ' meint. ${ }^{69}$ Die Aethiopes als ,die mit verbranntem Anblick' bilden so das passive Pendant zu Phaethon, der als aktiv Handelnder diesen Zustand seinem Namen nach als ,der Scheinende ${ }^{\text {verursacht. }}{ }^{70}$ Auf Ebene der Bezeichnungen - vergleichbar mit den verstetigten Produkten des Verwandlungsvorgangs selbst - ist damit resultativ das eingefangen und kunstvoll zueinander in Beziehung gesetzt, was auf Handlungsebene als ein Verhältnis von Subjekt (Phaethon) zu Objekt (Äthiopen) prädiziert ist. Der besondere Witz an der zusätzlichen Einschränkung credunt (235) ist es deshalb, dass Ovid den Vorbehalt dort gegenüber einem solchen Bedeutungszusammenhang äußert, wo er ihn mit höchster Sprachkunst inszeniert.

Er selbst bereitet diese Verknüpfung anhand seiner von medizinischer Akribie zeugenden Darstellung motivisch vor (met. II, 231-236) und nimmt sie sogar durch ein andeutungsvolles Spiel mit Namen und Wortbedeutungen zu Beginn der Geschichte vorweg (met. I, 776-779). Denn schon dort sind gewissermaßen alle Zutaten für die kommende Katastrophe gegeben: Die Aethiopas (778) werden in Form eines Anachronismus mit einem Namen bezeichnet, dessen Ursprung erst noch erzählt wird; ferner sind sie mit einem vordergründig possessiven, aber rückwirkend betrachtet auch kausal zu verstehenden suos (ebd.) beschrieben: Phaethon hat die Äthiopier nicht nur als seine Landsleute, sondern auch als seine Äthiopen anzusehen; und schließlich wird sogar die Ursache durch eine vermeintlich direkt daran anschlie-

67 So (in Übersetzung) Barchiesi ${ }^{4} 2013$, ad loc.

68 Dies bestärken sowohl die in met. I, 778 beobachteten Andeutungen als auch der sehr ähnliche Bau der beiden Hemiepeis bei gleicher Position im Vers: Aethiopasque suos (met. I, 778) und Aethiopum populos (met. II, 236).

69 Die Ableitung von $\omega ̋ \psi$, die Michalopoulos 2001, 21, zusammen mit ő $\psi$ vorschlägt, ist für Aethiops irreführend: In Aïí-o $\psi$ steht der jüngere Kurzvokal, während $\omega ٌ \psi$ laut Frisk nur in stehenden Ausdrücken v. a. bei Homer überliefert ist und als Dehnstufe selbst auf ő $\psi$ zurückgeht.

70 Zur Etymologie s. o. S. 134, Anm. 60. 
ßende Eigenschaft - als handelte es sich um ein zweites Attribut zu Aethiopas - erwähnt, nämlich positosque sub ignibus (ebd.). Nur durch die Ergänzung von Indos (ebd.) ist das verhindert. ${ }^{71}$

Erwähnenswert ist noch, dass der Anachronismus wie schon bei der Behauptung, die Argo sei das erste Schiff (VI, 721), am Buchende steht und dass in beiden Fällen gerade ein Aufbruch zu einem anderen Ort erfolgt, der dann zu Beginn des darauffolgenden Buches in den Fokus rückt. In einem solchen Moment, der eine gewisse Erwartung gegenüber dem Kommenden aufbaut, bewirkt die erzählerische Intervention so einen weiteren witzig-desillusionierenden Effekt und verstärkt dieses spielerische Setzen und Entgegensetzen von Zeit- und Bedeutungsdimensionen.

\subsubsection{Pygmalion, der paphische Held (met. X, 290-292)}

In einer vereinfachten Version liegt das identische Schema - Gebrauch einer namentlichen Bezeichnung, die ihre eigene Etymologie vorwegnimmt - auch noch bei Pygmalion vor. Nachdem dieser eine Frauenfigur erschaffen hat, die sich unter göttlichem Beistand in ein lebendiges Wesen verwandelt, schließt der Bericht folgendermaßen an:

tum vero Paphius plenissima concipit heros

[290] verba quibus Veneri grates agit, oraque tandem ore suo non falsa premit; ${ }^{72}$

Wie schon bei der Phaethon-Geschichte dient eine zeitliche Markierung (tum vero 290) einerseits als Signal für das Einsetzen eines neuen Handlungsaspekts: Nachdem unmittelbar zuvor in der für Ovid typischen Bildlichkeit der Prozess des LebendigWerdens der Statue geschildert und zuletzt durch ein Fühlen des Pulses (temptatae pollice venae - 289) mit wissenschaftlicher Akribie als fiktive Realität verifiziert wurde, schließt das mit Vers 290 einsetzende Geschehen dies schon als vorliegendes Resultat ein. Andererseits bringt dieses tum wiederum eine zeitliche Fixierung in der fiktiven Gegenwart zur Geltung, die sich noch als ambivalent erweisen soll.

Zunächst sind aber zwei andere Dinge merkwürdig: nämlich dass Pygmalion als ein Mensch, dessen letzte Taten waren, sich sofort nach der Rückkehr in sein Haus zu einer Statue ins Bett zu legen, sie zu küssen und ihren weicher werdenden Körper zu betasten $(280-283)$, als heros $(290)$ bezeichnet wird. ${ }^{73}$ Und des Weiteren scheint der

71 Das Aition zur dunklen Hautfarbe müsste sich wohlgemerkt auf die in der Antike als benachbart gedachten Äthiopier und Inder gleichermaßen beziehen. Vgl. Bömer 1969, ad met. I, 774 und 779. Vgl. zu weiteren möglichen Sprachspielen im Kontext der Phaethon-Geschichte Feldherr 2016.

72 Met. X, 290-292: ,Dann aber fasst der paphische Held die vollsten Worte, mit denen er Venus dankt, und drückt seinen eigenen Mund auf das nicht-falsche Antlitz.

73 Vgl. Anderson 1972, ad loc. Zu ergänzen wäre noch ein möglicher Kontrast zu der kurz zuvor stehenden (ebenso ambivalenten?) Antonomasie des Aias als fortissimus heros (met. X, 207). Laut Bömer 
Ausdruck plenissima verba concipere (wörtlich ,die vollsten Worte empfangen“ - 290 f.) so ungewöhnlich zu sein, dass er von den Kommentatoren entweder gar nicht oder im Falle Bömers - nur ausweichend erläutert wird..$^{74}$ Dass Ovid hier eine Aussage auf verba concipere verkürzt, für die er in met. XIV, 365 einen ganzen Vers verwendet concipit illa preces et verba precantia dicit (,jene formuliert Bitten und spricht ihre bittenden Worte aus') - liegt auf der Hand und bereitet für sich genommen keine Verständnisprobleme. ${ }^{75}$ Weshalb diese Worte (verba) aber plenus sein müssen, erschließt sich daraus nicht, ebenso wenig ist damit erklärt, warum ein eigentlich so schlichter Gedanke zu einer Katachrese verkürzt und von einer deplatzierten Antonomasie (heros) kontrastiert wird.

Beachtet man aber, dass - wie bei Ovid nicht selten $-{ }^{76}$ ein zum Verständnis der Satzprädikation wichtiges Wort (verba) als Enjambement am Anfang des nächsten Verses steht, wodurch es der Wahrnehmung gewissermaßen aufs Erste entzogen wird, scheint der Erzähler angesichts der expliziten Nennung von Venus (291) mit plenus und concipere einen zusätzlichen Bedeutungszusammenhang schon anzudeuten. Beide Wörter verbalisieren typischerweise einen Kernaspekt im Kontext von Schwangerschaft: Empfängnis (concipere) und Zustand des Schwanger-Seins (plenus). ${ }^{77}$

Dass Pygmalion aus diesem Grund schon zum heros gemacht werden sollte, darf mit Recht bezweifelt werden; allerdings erlangt der Befruchtungsaspekt, auch wenn er nicht direkt angesprochen wird, hier zusätzliches Gewicht. Denn bei der Bezeichnung von Pygmalion als Paphius ... heros (290) wird genau das vorweggenommen, was als Resultat der Schwangerschaft dazu führt, dass er überhaupt so genannt werden kann: seine Tochter Paphos. Dieser Umstand - und dadurch ist das Attribut ein Anachronismus - wird in Form einer abschließenden Aitiologie wenig später noch eigens vorgebracht:

22016, ad loc., ist dies überhaupt der einzige Fall, dass für Pygmalion in klassischer Dichtung heros genutzt wird.

74 Wie z.B. sind, um die Anmerkung von ebd., ad loc., aufzugreifen, ,vollständige 'Worte zu verstehen? Ist es eine lexikalische, syntaktische, semantische oder doch eine anlass- und adressatenspezifische Vollständigkeit? Und wozu braucht es dafür den übertrieben wirkenden Superlativ (Bömers Hinweis auf met. II, 763 ist nicht hilfreich, weil dort ein Genitivattribut vorhanden ist)?

75 Vgl. (zu concipere in diesem Kontext) Bömer 1977, ad met. VIII, 682. Um eine Eidformel, d. h. verbis conceptis, und einen diesbezüglichen Kontext (so der Weiterverweis bei Haupt/Korn ${ }^{5} 1966$, ad loc.) geht es hier aber nicht. Allerdings zeigt eine Petron-Stelle, dass auch diese Eidformel ironisch-übertrieben gesteigert werden kann: iurat verbis Eumolpus conceptissimis (,Eumolp schwört in den förmlichsten Worten` - Petron. CXIII, 13).

76 Am prominentesten wohl in met. I, 1f.: in nova fert animus | mutatas | dicere formas/ corpora. 77 So wird Myrrha, Pygmalions Ur-Enkelin, in der unmittelbar nachfolgenden Geschichte, nachdem sie von ihrem Vater im Bett aufgenommen, wörtlich: ,akzeptiert' (accipit - met. X, 465), und geschwängert wurde, als plena patris (,voll', i. S. v. ,schwanger vom Vater - 469) bezeichnet. Vgl. (u. a. zu dieser Ambivalenz) Bömer 22016, ad loc. 
coniugio, quod fecit, adest dea, iamque coactis cornibus in plenum noviens lunaribus orbem illa Paphon genuit, de qua tenet insula nomen. ${ }^{78}$

Unterstützt dadurch, dass die beiden Stellen sehr nah beieinander stehen, rekurriert die Etymologie deutlich auf ihre vorherige Antizipation: Der Name Paphos (297) als auch seine Funktion bezüglich der Realität (ausgedrückt durch den Relativsatz 297) wird explizit genannt; weiterhin ist erneut Venus (dea - 295) zugegen, diesmal als Metonymie für den Geschlechtsverkehr, also genau den Vorgang, der zu einer conceptio führt; und letztlich wird auch die Schwangerschaft durch das Mondmotiv an sich (cornibus ... lunaribus - 296) ${ }^{79}$ sowie den Zeitraum (noviens - ebd.) wieder aufgegriffen und wohl durch die Lexemrepetition bei plenum (ebd.) gegenüber dem auffälligen plenissima (290) zusätzlich verdeutlicht.

Vieles spricht dafür, den Anachronismus bei Paphius über das bloße Vorliegen hinaus ${ }^{80}$ in eine engere Beziehung zu den Umständen zu setzen, in denen er einerseits zur Sprache gebracht wird - nach dem Lebendig-Werden von Pygmalions Kunstwerk und wodurch er andererseits bedingt ist - in der antizipierten und über semantischsyntaktische Wiederholungen verknüpften Schwangerschaft. Denn in einer vom Erzähler zeitlich markierten Situation (tum vero - 290), in der die Grenze von Fiktion und Wirklichkeit durchlässig geworden zu sein scheint, ist von Seiten der Erzählung die zeitlich-logische Determination dieses diegetischen Jetzt destabilisiert. Während die Statue in der fiktiven Welt als Wesen ,nicht falsch' (non falsa - 292 (bezogen auf ora)), d. h. real wird, erweist sich so der bis dahin fiktiv-reale Pygmalion durch beide ihm zugeschriebenen Eigenschaften als falsus.

Das Faszinierende daran ist, dass er über die angedeutete, aber gleichermaßen verfrühte Schwangerschaft trotz seiner fiktiven Falschheit bereits buchstäblich mit dem Gedanken schwanger geht, der die vermeintlich richtigen Verhältnisse, wie sie dann in met. X, 295-297 erzählerisch nachgeholt werden, wiedereinsetzen wird. Auf diese Antizipation könnte daher mit plenissima (290) - eben, weil plenus sowohl in seiner Grundbedeutung als Attribut zu verba eine markante Leerstelle aufweist als auch, weil es durch die Steigerung als merkwürdig hervorsticht - hingewiesen sein. Schon formal ließe sich dafür im Hyperbaton Paphius plenissima concipit heros (290) ein schwaches Anzeichen finden: Darin ist das Motiv der Schwangerschaft plenissima concipit als die zugrunde liegende innere Ursache von der Bezeichnung Paphius ... heros auf der im Vers wie auch im sprachlichen Zeichen äußeren Ebene eingeklammert.

78 Met. X, 295-297: ,Dem Ehebund, den sie geschaffen hat, wohnt die Göttin bei, und jene, nachdem schon neunmal die Hörner des Mondes zu einem vollen Kreis vereinigt worden sind, gebar Paphos, von der die Insel den Namen hat.`

79 Vgl. Bömer 22016, ad loc. und Tronchet 1998, 103f. Zum Horn-Motiv an dieser Stelle s. Feldherr 2010, $271 \mathrm{f}$.

80 Worauf sich im Wesentlichen die knappen Kommentare bei Anderson 1972; Bömer ${ }^{2} 2016$ und Reed 2013, ad loc. beschränken. 
Darüber hinaus ist ein solches Verschwimmen von Zeit- und Wirklichkeitsdimensionen an dieser Stelle auch in einer anderen Weise relevant, die noch einmal mit der in der diegetischen Handlung so unpassend wirkenden Antonomasie heros zu tun. Nach der konventionellen Mythentradition ist nämlich nicht Pygmalion, sondern sein Enkel Kinyras der Stifter des Venus-Kults auf Zypern. ${ }^{81}$ Folglich liegt in dieser durchaus eigenwilligen Umdeutung, in der Ovid bzw. sein Sprecher Orpheus sogar die ganze Insel umbenennt - die Aussage de qua tenet insula nomen (297) wird in met. X, 530 abgewandelt wiederholt $-{ }^{82}$ eine weitere zeitliche Abweichung. Diese ist, wie weiter unten noch genauer zu diskutieren sein wird, ein poetischer Synchronismus, weil in den „Metamorphosen“ eine Kultstiftung selbst nicht erzählt wird; ${ }^{83}$ sie fordert gleichfalls dazu auf, die von der Aitiologie behauptete Beziehung eines realen gegenwärtigen Phänomens, d. h. der Zuschreibung eines Attributs bei einem Objekt oder einer Person, mit der von ihr behaupteten Vergangenheit zu reflektieren. ${ }^{84}$

Während der Anachronismus die diesen Zusammenhang vermittelnde Erzählung als nicht-objektives Medium ausweist, dürfte sich dies somit im Synchronismus auf einer zusätzlichen Ebene spiegeln: Dabei wird deutlich, dass Orpheus kein faktuales Narrativ zur Geschichte Zyperns, sondern die Fiktion einer wundersamen bzw. wunderlichen Familien-Dynastie darbietet, welche mit Pygmalion einsetzt und den quantitativen wie thematischen Hauptteil seines Gesangs bildet. ${ }^{85}$ In einer solchen, durchaus ambivalenten Funktion kann er mit einem gewissen Recht als Paphius heros bezeichnet werden.

Die zuletzt noch zu thematisierende Parallele zwischen den beiden anachronistischen Etymologien zu Aethiopes und Paphius erscheint unwirklich, ist aber eben deshalb einem Dichter wie Ovid rundheraus zuzutrauen. Konkret geht es darum, dass ausgerechnet bei diesen beiden Fällen die entsprechende Figur eine merkwürdig voreilige Handlung mit concipit vollführt: Phaethon einerseits hört mit Freude die Worte seiner Mutter, die mit keinem Wort vom Himmel gesprochen hat, stürmt los und - seltsamerweise - ,fasst den Äther im Geiste‘ (concipit aethera mente - met. I, 777), woran sich Aethiopasque suos (778) direkt anschließt. In Anbetracht der eigentlichen Bedeutung von $\alpha$ i $\theta \eta \rho$ als ,oberste, brennende Luftschicht' liegt auch darin eine Vorwegnahme der späteren Katastrophe als der Ursache für den Namen Aethiopes: Er denkt hier also schon unbewusst an die ,brennende Luft', wie sie im weiteren Verlauf

81 Vgl. Bömer 22016, 94.

82 Dort ist von Paphon aequore cinctam (,das vom Meer umgebene Paphos“ - met. X, 530) die Rede, was auf die eigentlich diesen Namen tragende Stadt nicht zutrifft und außerdem ein stehendes Bei-

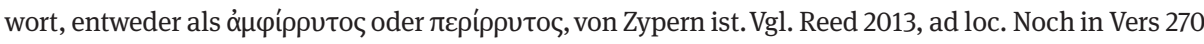
wie auch dann in Vers 718 wird die Insel Cyprus genannt.

83 S.u. Kap. 6.1. Ein Kult ist in Gestalt der festa dies Veneris tota celeberrima Cypro (,der Festtag der Venus, auf ganz Zypern der feierlichste - met. X, 270) schließlich schon vor Verwandlung der Statue etabliert.

84 Vgl. Feldherr 2010, 271.

85 Wie noch zu sehen sein wird, zeigen sich darin auffällige Parallelen im Allgemeinen zum Synchronismus, besonders aber zu dem bei Pythagoras. S.u. Kap. 6.4. 
fiktive Realität wird. Andererseits vollzieht ein unzutreffend als Paphius heros bezeichneter Mann mit plenissima concipit ... verba (290f.) einen Vorgang, der sich in der eigentlichen, konkret zu verstehenden Bedeutung nicht restlos erschließt. ${ }^{86}$. In der uneigentlichen Semantik aber, d. h. in der über diese Worte angedeuteten Schwangerschaft, ${ }^{87}$ weist er damit aber schon auf genau diejenigen Umstände hin, die sowohl die Statue schwanger werden lassen als auch - das ist das Erstaunliche - die auf ihn selbst bezogenen Worte (verba), nämlich Paphius ... heros, tatsächlich mit Sinn füllen und in der ovidischen Ironisierung gar die ,vollsten` (plenissima) sind.

\subsubsection{Kallisto (met. I, 64; met. II, 132 und 171f.)}

Im nächsten nun vorzustellenden Fall eines Anachronismus ist es eine sogar verschiedentlich benannte Erscheinung, die vor ihrer fiktional vermittelten Realisierung fiktive Realität ist. ${ }^{88}$ Ehe Phaethon im zweiten Buch die Welt in Flammen setzt, sind es zunächst die Gestirne, die die Folgen des ungezügelten und deshalb vom Weg abkommenden Sonnenwagens zu spüren bekommen. ${ }^{89}$ Die Schilderung dazu setzt folgendermaßen ein:

tum primum radiis gelidi caluere Triones

et vetito frustra temptarunt aequore tingi. ${ }^{90}$

Wenn auch zum Teil wohl dadurch bedingt, dass Triones (171) als das erste von mehreren auf die Hitze reagierenden Sternbildern erwähnt ist, so ist es doch erstaunlich, dass mit tum primum (ebd.) erneut das diegetische Geschehen zeitlich ex-

86 Vielsagend ist hierzu die Bandbreite der vorgeschlagenen und im Folgenden in Auswahl vorgestellten Übersetzungen: Am direktesten: „did the Paphian hero offer up the fullest words“ (Hill 1999); dann vor allem eine Quantität betonend: „the hero, of Paphos, was indeed overfull of words“ (Kline 2000); „sucht der paphische Künstler [sic] seinen Dank in eine Fülle feierlicher Worte zu fassen“ (Fink 2004) und „this hero of Paphos found a host of words“ (Ambrose 2004); und schließlich bezogen auf die innere Anteilnahme: „erhebt der paphische Held vollströmende Worte“ (Voß (in: o. H. 2005)); „dankt der Held von Paphos mit Worten, die aus vollstem Herzen strömen“ (von Albrecht 2010); „Worte aus voller Brust [...] faßt der Paphier da“ (Rösch (in: Holzberg $\left.{ }^{14} 1996\right)$ ) und „l'eroe di Pafo formula parole d'incontenibile gioia“ (Chiarini (in: Reed 2013)).

87 Die Reminiszenz zum eingangs geäußerten Beginn der Liebe - operisque sui concepit amorem (, und ihn ergriff die Liebe zu seinem Werk ${ }^{\star}$ - met. X, 249) - spielt als Kontrast sicherlich auch eine Rolle, weil hinter den Worten, die er in met. X, 290 f. fasst, so gesehen das steht, was er tatsächlich schon, gefasst ${ }^{\star}$ hat: nämlich seinen amor zur Statue.

88 Nach den kurzen Anmerkungen an früherer Stelle dazu (s. o. Kap. 4.1.2) und weil dieses wie auch das nächste Beispiel (Atlas) schon ausreichend Beachtung gefunden haben (vgl. zu Kallisto v.a. Tronchet 1998, 371-388; Wheeler 1999a, 128-130; Zissos/Gildenhard 1999 und die entsprechenden Anmerkungen bei Bömer, Anderson und Barchiesi), kann sich die nachfolgende Besprechung auf das Wesentliche beschränken.

89 Vgl. dazu Loos 2008, 285.

90 Met. II, 171f.: ,Damals ist wegen der Strahlen zum ersten Mal der kühle Große Bär erglüht und hat versucht, sich vergebens mit verbotenem Gewässer zu benetzen.‘ 
plizit festgelegt ist. ${ }^{91}$ Durch den Zusatz von primum ist die Existenz des fiktiven Objekts sogar nachhaltig betont. ${ }^{92}$ Außerdem wird dies davon bestärkt, dass sowohl die Erscheinung selbst (Triones) mitsamt Kälte als einem ihrer schon zuvor genannten Charakteristika (gelidi - met. II, 171) zur Sprache kommt als auch eine mit ihr zusammenhängende Gesetzmäßigkeit (vetito ... aequore - 172), die offenbar so zwingend ist, dass nicht einmal in einer derartigen Notsituation eine Ausnahme gestattet ist (daher: frustra - ebd.). ${ }^{93}$

Das ursächliche Ereignis, das zur Besonderheit dieses Phänomens führt, ereignet sich aber dann erst einige hundert Verse später, als Jupiter nach dem Weltenbrand auf eine Kontrollfahrt geht, dabei Kallisto erblickt und sich an ihr vergeht. ${ }^{94}$ Durch die Anzeichen ihrer Schwangerschaft wird sie von Diana symbolisch und faktisch aus ihrer Gefolgschaft ausgeschlossen - auch hierbei wird ihr ein Bad im Wasser verwehrt - und von Juno nach der Geburt ihres Kindes Arkas in eine Bärin verwandelt. ${ }^{95}$

Um den paradoxen Zustand zu veranschaulichen, dass sie in ihrer neuen Tiergestalt - weil sie ,vergaß, was sie war' (oblita, quid esset - met. II, 493) - Angst vor Bären und Wölfen hat, kontrastiert Ovid dies mit der Aussage, dass sie ein solches Verhalten zeige, obwohl sich doch ihr in einen Wolf verwandelter Vater Lykaon unter diesen befindet: quamvis pater esset in illis (495). Hieran offenbart sich ein erstes signifikantes Abweichen von der bislang offenbar gültigen erzähllogischen Prämisse: Im ersten Buch war es Lykaon, der mit seiner Verkommenheit den finalen Anstoß für die Vernichtung der Menschheit durch die große Flut gegeben hat. ${ }^{96}$ Der Erzähler durch die Augen Jupiters blickend - versäumt es dabei nicht, hinzuzusetzen, dass das

$91 \mathrm{Zu}$ dieser Zeitlichkeit im allgemeinen Kontext von Aitiologie vgl. Walter 2020, 18-22.

92 Konkret kann dies sogar bis zur Weltentstehung zurückverfolgt werden, da der mundi fabricator (met. I, 57) dabei den Winden ihren Platz zuweist und es zum Nordwind heißt: Scythiam septemque Triones/ horrifer invasit Boreas (,Nach Skythien und zum Siebengestirn ist der schaurige Boreas hingestürmt.‘ - met. I, 64f.). Zudem kennt Sol, als er seinem Sohn die letzten Instruktionen gibt, die iunctam aquilonibus Arcton (,die mit den Nordwinden verbundene Bärin‘ - met. II, 132).

93 Unklar ist aber, ob Ovid es mit Triones, was eigentlich trio ,Dreschochse' heißt und durch die Assoziation mit einem Ochsenwagen ein Siebengestirn (daher lat. Septentriones) genannt wurde (vgl. Bömer 1969, ad loc.), vermeidet, die Verwandlung Kallistos in einen Bären vorwegzunehmen (so Anderson 1997, ad loc.). Aufgrund der vorherigen Nennung der gelida Arctos, der leicht verständlichen Charakteristika und auch des Umstandes, dass Bär und Wagen wohl in enger Verbindung gedacht wurden (auch Iuno spricht am Ende der Geschichte von Kallisto nicht als Bärin, sondern septem ... Triones (528); vgl. auch Bömer 1969, ad met. II, 177), muss dies in Zweifel gezogen werden. Freilich würde dies aber gut ins Bild passen, da Kallisto, wie Zissos/Gildenhard 1999, 40, anmerken, in der sie betreffenden Geschichte immer nur in Antonomasie genannt wird. Zudem ist sonst das Sternbild lediglich allgemein und zusammen mit Arkas als vicina sidera (met. II, 507), stellas (516) und sidera (529) erwähnt.

94 Weltenbrand und Kallisto-Geschichte sind daher verschiedentlich und eng aufeinander bezogen. Vgl. ebd., $39 \mathrm{f}$.

95 Vgl. Bömer 1969, ad met. II, 171 und 464. Aber nicht Jupiter, wie es bei Wheeler 1999a, 128, heißt, verwandelt sie, sondern Juno. Das ist für den inneren Ablauf der Geschichte von großer Wichtigkeit. 96 Vgl. ebd., 129. 
fromme Paar Deukalion und Pyrrha, die im Anschluss mit der Kreation der neuen Menschenart betraut werden, die einzigen „,vom alten Schlag“ Übrigen sind:

et superesse virum de tot modo milibus unum

et superesse videt de tot modo milibus unam. ${ }^{97}$

Zwar ist darin nur impliziert, dass der zu einem Tier verwandelte Lykaon ebenso umgekommen ist, aber auf seine Tochter Kallisto trifft die Aussage zu, gerade wenn dabei so viel Wert auf die buchstäbliche Einzigartigkeit der Überlenden gelegt wird. Indem Ovid im zweiten Buch auf das genealogische Prinzip zurückkehrt, schränkt er daher rückwirkend den Wahrheitsgehalt dieser Aussage ein.

Das ist zwar an sich kein Anachronismus, weil Zeitlichkeit nicht den Kern des Widerspruchs ausmacht, ${ }^{98}$ die Erzählung als vermittelnde Instanz ist damit aber gleichermaßen problematisiert. ${ }^{99}$ Und Lykaon tritt im Zuge dessen nicht nur wie in met. II, 495 als das in Erscheinung, wozu er gemäß Ovids Erzählung gemacht wurde, sondern in zwei weiteren Stellen, in denen auf bemerkenswerte Weise die paradoxen Verhältnisse in dieser Familie betont werden.

So besteht die Tragik am Schluss der Geschichte darin, dass Arkas einerseits ein begeisterter Jäger ist, aber seine Mutter nicht kennt, Kallisto sich jedoch andererseits ihrer Animalität nicht bewusst ist und sich ihm nähert. Eine besondere Pointe ist es, dass Arkas als Lycaoniae proles ignara parentis (,Nachkomme, unkundig über sein lykaonisches Elternteil` - 496) eingeführt wird. Denn die diegetische Figur Arkas ist sich mit Sicherheit nicht bewusst, dass über seinen Kopf hinweg die Ausdrücke Lycaoniae parentis und proles zur Ironisierung des Erzählerberichts genutzt sind. ${ }^{100}$ Gleichermaßen markant ist dies im zweiten Fall, in dem sich die gekränkte Juno über die Zumutungen von Jupiters Frauenabenteuern entrüstet und unter anderem Folgendes anbringt:

vindicet antiquam faciem vultusque ferinos

detrahat, Argolica quod in ante Phoronide fecit!

cur non et pulsa ducit Iunone meoque

conlocat in thalamo socerumque Lycaona sumit? ${ }^{101}$

97 Met. I, 325 f.: ,Dass übrig ist von so vielen Tausenden einer, dass übrig ist von so vielen Tausenden eine, sieht er.'

98 Denn diese ist sowohl in der Beziehung von Vater und Tochter als auch in Bezug auf die Metamorphose stimmig.

99 Statt von einer „temporal inconsistency“ (Wheeler 1999a, 129) ist präziser von einer erzähllogischen Inkonsistenz auszugehen. Vgl. Tronchet 1998, $379 \mathrm{f}$.

$100 \mathrm{Vgl}$. Zissos/Gildenhard 1999, 40 f. Angesichts der Unwissenheit des Arkas könnte man sogar noch einmal zu seiner Mutter selbst zurückgehen und fragen: Hätte sie denn wissen können, dass ihr Vater ein Wolf ist oder war auch das nur ein gekonnter Witz des Erzählers? Der Kommentar und seine Pointe in met. II, 495 setzen ein solches Wissen als Möglichkeit voraus.

101 Met. II, 523-526: ,Soll er doch ihr altes Aussehen wiederherstellen und das Gesicht eines Tieres von ihr nehmen, was er vorher schon bei der argolischen Phoroniden gemacht hat. Warum nicht auch 
Die Vorstellung Junos, dass sich Jupiter mit der Wahl Kallistos ausgerechnet Lykaon als Schwiegervater (socer - 526) ins Haus holen würde, setzt ebenso bei der Genealogie an, entfaltet aber ihre volle Geltung erst angesichts der im ersten Buch geschilderten Freveltaten Lykaons und ihrer Folgen. ${ }^{102}$ Juno stellt ihn sich demnach als lebenden oder lebhaft erinnerten Vater Kallistos vor. Eine zusätzliche Verknüpfung erfolgt einerseits in zeitlicher Hinsicht mit ante (524), womit impliziert ist, dass die früheren Ereignisse und ihre Folgen nach wie vor gültig sind; andererseits erfolgt sie hinsichtlich des Strafmotivs auch über die Parallele zur Io-Geschichte, da sie dort wegen eines Versprechens Jupiters zuletzt Ios Rückverwandlung zu- und von ihrer Bestrafung abgelassen hatte. ${ }^{103}$

Das Betonen der Genealogie unterminiert so das implizite zeitliche Voranschreiten der Erzählung mitsamt der von ihr dargebrachten Metamorphosen - als Bewegungen von Zustand A zu Zustand B sind auch sie Prozesse in der Zeit. ${ }^{104}$ Der eigentliche Anachronismus beim Sternbild fügt sich in dieses komplexe Ensemble an legitimierenden und destabilisierenden Sinnzusammenhängen gut ein und nutzt dazu effektvoll die zeitliche Dialektik aus diegetischem Jetzt und dem extradiegetischen Jetzt aus.

Der Katasterismos selbst erfolgt in einem Moment höchster Dringlichkeit, in dem die gegensätzliche und unumkehrbare Handlung schon in Vorbereitung ist: Arkas ,war gerade dabei, ihre Brust mit dem wundenschlagenden Geschoss $\mathrm{zu}$ treffen (vulnifico fuerat fixurus pectora telo - met. II, 504), als Jupiter sie im letzten Augenblick rettet:

\section{et volucri raptos per inania vento \\ imposuit caelo vicinaque sidera fecit. ${ }^{105}$}

Mit großem Nachdruck wird allein hier die Eile geschildert, sodass Jupiters Handeln überhastet und gerade gegenüber der hervorgehobenen Allmacht des Gottes - omnipotens heißt es in met. II, 505 - unbedacht wirkt. ${ }^{106}$ Juno bestätigt das sofort mit ihrer unmittelbar darauffolgenden Reaktion. Denn durch die Verstirnung wird nicht

heiratet er sie, nachdem Juno verstoßen worden ist, und platziert sie in mein Gemach und nimmt sich Lykaon zum Schwiegervater?

102 Vgl. Tronchet 1998, 380 und Wheeler 1999a, 129f.

103 Jupiter leistet dort aber kein „promise of marital fidelity“ (ebd., 129), sondern verspricht gegenüber Juno nur: ,diese wird dir niemals Grund zum Schmerz sein“ (numquam tibi causa doloris/ haec erit - met. I, 736f.). Das meint er aus gutem Grunde nur in Bezug auf Io (haec).

104 S. dazu u. Kap. 7.2.1.1.

105 Met. II, 506f.: ,und raffte sie mit einem flüchtigen Wind durch den leeren Raum weg, setzte sie auf den Himmel und machte sie zu benachbarten Sternen. 'Zur Funktion des PFA s.u. Kap. 6.2.1.1. Zur Stelle vgl. Schmitzer ${ }^{2} 2016 \mathrm{a}, 107 \mathrm{f}$.

106 Vgl. zum ganzen Satz (met. II, 505 - 507) die Beobachtungen zur „Eile, mit der Jupiter vorgeht“, bei Bömer 1969, und (mit Betonung von Jupiters Inkompetenz) Anderson 1997, ad loc. Zu Macht und Allmacht in der Kallisto-Geschichte s. Heldmann 2011, 53-57. 
nur ihre ursprüngliche Bestrafung an Kallisto - die Verwandlung in eine Bärin - ihrer negativen Wirkung enthoben, sondern sogar noch in ihr allerorts sichtbares Gegenteil verkehrt, weil nun ,die Geliebte zwischen den Sternen strahlte، (inter sidera paelex) fulsit - met. II, 508f.). Die notbehelfsmäßige Rettung von Arkas und Kallisto steht damit in kausaler Relation zur zusätzlichen Kränkung Junos. Letztlich ist sie auch der Grund, bei Okeanos und Tethys als Vormund-Figuren um Hilfe zu bitten:107

,gurgite caeruleo septem prohibete Triones

sideraque in caelum stupri mercede recepta

pellite, ne puro tingantur in aequore paelex. ${ }^{{ }^{108}}$

Eine Erklärung aber, wie es zu dem Namen kommt, mit dessen Nennung in Vers 528 die Verbindung zum Anachronismus in met. II, 171 f. hergestellt ist, erfolgt damit aber nicht; vielmehr wird die Identität von Kallisto, dem Großen Bären (ursa maior) und den Triones schlichtweg behauptet, indem über die leicht redundant wirkende Koordination zweier Aufforderungen (prohibete und pellite - 528 und 530) eine Gleichheit der fiktiven Objekte Triones (528) und sidera in caelum stupri mercede recepta (529) impliziert ist.

Noch auffälliger ist das bei der zweiten im Vers 171 genannten Eigenschaft: Die dort in Antithese zur Hitze der ungezügelten Sonne stehende Kühle (gelidi) wird in Ovids Aitiologie nicht thematisiert. Denn für Jupiters improvisiert wirkende Notlösung spielt die Kühle weder direkt noch indirekt in Form der späteren Position des Sterns am Himmel eine Rolle; und für das von Juno angeregte Verbot, dass das Sternbild nicht ins Wasser tauchen darf, wodurch es nebenbei bemerkt umso sichtbarer ist, dürfte Kälte mitunter sogar kontradiktorisch sein. ${ }^{109}$ Trotzdem findet sich neben der explizit behaupteten (met. II, 132) und geographisch implizierten (met. I, 64) Ursache sogar ein verschlüsselter Hinweis dazu auch in Junos Rede: Mit der astronomisch versierten und durch videre in seiner Evidenz bestärkten Ortsangabe macht sie eine indirekte Angabe zum dortigen, d. h. in der Polarregion herrschenden Klima:

videritis stellas illic, ubi circulus, axem

ultimus extremum spatioque brevissimus ambit. ${ }^{110}$

107 Als Grund, von dem sich Okeanos und Tethys rühren lassen sollen, nennt sie dies in met. II, 527 explizit: contemptus.

108 Met. II, 528 - 530: ,Haltet das Siebengestirn fern von bläulichen Fluten und stößt die Sterne davon, die durch den Lohn der Unzucht in den Himmel aufgenommen wurden, damit sich nicht die Geliebte im reinen Meer benetzt.'

109 Denkt man das Motiv einmal zu Ende, erscheint es plausibler, dass dem Stern in der Folge eher warm oder heiß wird, wenn ihm die Erfrischung im Wasser verwehrt ist.

110 Met. II, 516f.: ,Die Sterne könntet ihr an jenem Ort sehen, wo der Kreis den hintersten Pol als äußerster und in seiner Ausdehnung als kürzester umwandelt.' Zu den Details s. Bömer 1969, ad loc. 
Das ist aber gleichfalls nur eine Behauptung, mit der sich das Gegebene - und damit auch die mutmaßliche Gleichheit der Triones und der sidera - bestätigen lässt; eine Begründung jedoch dafür, warum der Stern an genau diesem Ort stehen muss, wird hier weder durch Juno noch durch den Erzähler an anderer Stelle gegeben. Ganz im Gegenteil macht dieser durch den dreimaligen Superlativ (ultimus, extremum, brevissimus - 517) übertrieben wirkende Verweis sogar die Aitiologie der Haupterzählung obsolet, weil sich daraus folgern lässt, dass das Sternbild so weit im Norden steht, dass es den Horizont ohnehin nicht erreicht. Folglich bräuchte es das Verbot - und jenes „comically motivated aition“111 - gar nicht. Diese für Junos gekränktes Ego so wichtige Strafmaßnahme geht wie schon all die anderen zuvor in ihrer Wirkung fehl: ${ }^{112}$ Sie dient buchstäblich nur dem schönen Schein.

Nicht unwichtig aber ist es, dass am Ende der Kallisto-Geschichte dann mit der wörtlichen Wiederholung der Triones (528) die mit der Erstnennung in Vers 171 aufgegebene Erzählordnung wiedereingesetzt ist. Denn so hat nun das zweite, etwas komplexere Paradoxon sein nachträgliches mythisches Aition, dass die Triones vergebens in das verbotene Gewässer einzutauchen versuchen (met. II, 172). Parallel zu der mit Phaethon aus den Fugen geratenen und nun re-etablierten Ordnung in der diegetischen Welt ist damit auch die extradiegetische Erzählung harmonisiert: ${ }^{113}$ Eine weitere Genealogie mit dieser Familie wird es nicht geben und die diegetische Welt ist wieder synchron zum Standpunkt des Erzählers.

\subsubsection{Atlas (met. II, 296f.)}

Die im Unterschied aus diegetischer und realer Erscheinung liegende Ambivalenz, die zusätzlich von einer Erzählinstanz sowohl über vermeintlich zuverlässige Aussagen verringert als auch über offene Kontradiktionen forciert wird, liegt in gesteigerter Form bei Atlas vor, da sie rekurrierend über mehrere, nicht aufeinanderfolgende Bücher thematisiert wird.

Gleichfalls im Umfeld der Phaethon-Geschichte - als der Weltenbrand solch extreme Dimensionen angenommen hat, dass die Erde in Personifikation an Jupiter herantreten und um Abhilfe bitten muss ${ }^{114}$ wird der Zustand der Welt in die folgende, bestenfalls dann auch Jupiter überzeugende Anschauung gefasst:

111 Otis ${ }^{2} 1970,119$.

112 Es handelt sich um eine witzige Form der tragischen Ironie, dass es ausgerechnet Juno ist, die das Sternbildes so exakt in den wörtlich nördlichsten Norden lokalisiert, aber nicht begreift, dass dies ihr eigenes Anliegen beträchtlich schmälert.

113 Auf die wesentlichen Parallelen aus Kreation und Re-Kreation im ersten und zweiten Buch machen unter Beachtung der Anachronismen Tronchet 1998, 379-384 und Zissos/Gildenhard 1999, 46f., aufmerksam.

114 Verwunderlich ist es, dass Eggers 1984 bei seiner überaus detaillierten Auseinandersetzung mit der Tellus-Figur (92-105) gänzlich ausblendet, dass innerhalb oder im Umfeld dieser anthropomorphen Erd-Gottheit mit Atlas eine weitere menschlich-gedachte Naturerscheinung als tätiges Wesen 
fumat uterque polus. quos si vitiaverit ignis

[295] atria vestra ruent. Atlas en ipse laborat vixque suis umeris candentem sustinet axem. ${ }^{115}$

Was die Triones und die anderen Sternbilder zuvor im Speziellen exemplifizierten (met. II, 171-177), ist in Form der Pole, auf denen schließlich auch die göttlichen Wohnungen (atria - 296) stehen, ${ }^{116}$ in einer globalen Perspektive verdeutlicht. Hierzu gehört auch, dass Atlas den heißen Pol nur mit Mühe tragen kann, ausgedrückt in Form eines etymologischen Wortspiels: Mit seinen Tätigkeiten laborat (296) und sustinet (297) führt er selbst (ipse) vor, was sein Name im Griechischen bedeutet. ${ }^{117}$ Ähnlich, aber etwas impliziter als bei den Triones ist damit auch ein vorheriger Normalzustand ausgedrückt, worin ein Atlas, der das Himmelsgewölbe auf seinen Schultern trägt, einen angestammten Platz hat. ${ }^{118}$ Dieser anthropomorphe Wesenszug wird außerdem unter anderem am Ende des zweiten Buches via Genealogie bestätigt, ${ }^{119}$ da Merkur dort - in der Rolle eines Liebhabers, der seine Vorzüge herausstellen möchte - mit Stolz von sich behauptet: Atlantis/ Pleionesque nepos ego sum (,ich für meinen Teil bin der Enkel des Atlas und der Pleione‘ - met. II, 742f.).

Ein Novum in diesem Bedeutungsspektrum kommt dann im vierten Buch hinzu, als sich Perseus nach einem längeren und allem Anschein nach grund- und ziellosen Rundflug $^{120}$ zu einer Nachtruhe ,auf dem hesperischem Erdkreis, dem Reich des Atlas (Hesperio, regnis Atlantis, in orbe - met. IV, 628) entschließt. Für den Fall allerdings, man hielte die Apposition regnis Atlantis für eine allgemeine Zuschreibung, sodass damit die vorherige Nennung von Atlas nicht infrage gestellt ist, findet sich gleich im Anschluss eine klare Korrektur:

hic hominum cunctis ingenti corpore praestans

Iapetionides Atlas fuit; ultima tellus

präsentiert ist (auf S. 98 wird zwar kurz auf Atlas eingegangen, aber anhand der Darstellung im vierten Buch und in einer solchen Weise, als spielte er in Bezug auf Tellus keine Rolle).

115 Met. II, 295-297: ,Jeder der beiden Pole raucht. Wenn das Feuer diese schädigt, werden eure Häuser einstürzen. Schau, selbst Atlas hat seine Mühe und kann kaum die glühende Himmelsachse auf seinen Schultern tragen.'

116 Genauer gesagt stehen sie nicht an den Polen, sondern gemäß der sehr konkreten Ortsbeschreibung im ersten Buch (met. I, 171f.) entlang der Milchstraße. Zu diesen Aktualisierungen s.u. Kap. 7.1.3.1.

117 Vgl. Michalopoulos 2001, 39. Laut Frisk eine Zusammenbildung aus kopulativem $\alpha$ und dem Stamm $\tau \lambda \alpha-$,ertragen, aushalten'.

118 Wie Wheeler 1999a, 132f., richtig herausstellt, geht es hier eindeutig um eine anthropomorphe Figur, die zunächst nichts mit einem Berg gemein hat.

119 Ebenso zu nennen sind die mehrmaligen Antonomasie Merkurs (met. I, 682; II, 704 und 834; met. VIII, 627) und des Merkursohnes Hermaphrodit (met. IV, 368) als Atlantiades.

120 Vgl. Barchiesi/Rosati 2007, ad met. IV, 321-328. Im Zuge dessen fliegt er nebenbei bemerkt dreimal an einem Sternbild namens gelidas Arctos (met. IV, 625) vorüber, das sich zuvor schon jener nautisch so begabte Akoites ,mit den Augen notiert‘ hatte (oculis Arctonque notavi - met. III, 595). 
rege sub hoc et pontus erat, qui Solis anhelis

aequora subdit equis et fessos excipit axes. ${ }^{121}$

Unmissverständlich deutlich ist allein hier sowohl sein Mensch- bzw. Menschlich-Sein als auch sein Wirken in der fiktiven Gegenwart: ${ }^{122}$ Schon das zweite Wort hominum (631) - als partitiver Genitiv in Verbindung mit cunctus eine ovidische Innovation lenkt als ungewöhnlicher Ausdruck die Aufmerksamkeit auf genau diesen Aspekt; dasselbe bewirkt erstens der über seinen Körper angestellte Vergleich (ebd.); zweitens eine weitere genealogische Einordnung über das Patronym Iapetionides (632), das vor Ovid in der lateinischen Form nicht überliefert ist; drittens seine persönliche Nennung als rex (633) und schließlich viertens die geradezu pittoreske Vorstellung, dass er wie ein Stallknecht den Pferden Sols Wasser bzw. einen ganzen Ozean (aequora - 634) unter ihre dampfenden Münder reicht (subdit - ebd.) und den durch die enorme Beanspruchung mitgenommenen Wagen in seine Obhut nimmt (excipit - ebd.). ${ }^{123}$

Darüber hinaus werden unterhalb dieser gleichsam an der Oberfläche erkennbaren Bedeutungsebene mit Nachdruck auch jene Charakteristika aufgerufen, die für den Atlas mit der Welt auf seinen Schultern in met. II, 296f. schon ex- oder implizit genannt worden sind: ein Gewichtsaspekt, der für die von ihm ausgeführte Tätigkeit durchaus relevant ist, und allgemein eine eher kosmisch-globale Perspektive, die sich im Sprechen von der ganzen Menschheit, der Erde und dem Meer sowie dem Sonnengott manifestiert; weiterhin die Lexemrepetition zum einen bei tellus (met. IV, 632) in Verbindung mit ultima, deren Rede im zweiten Buch eine wahrhaft ultimative Reaktion auf den Zustand der Welt war; zum anderen die Wiederholung bei axes (met. IV, 634), deren poetischer Plural im Kontext von Atlas die Auseinandersetzung mit der Doppeldeutigkeit des Wortes axis als hier primär gemeinte ,Wagenachse und als ,Himmelsachse، (so in met. II, 297) förmlich einfordert. ${ }^{124}$ Zuletzt wird auch mit der personifizierenden Attribuierung der axes als fessos (634) die etymologisch-spielerische Ausdeutung von Atlas Namen wiederaufgriffen, was als Anachronismus auf den eigentlich erst in Atlas' späterer Funktion eintretenden Erschöpfungszustand hinweist.

121 Met. IV, 631-634: ,Hier war Atlas, der Sohn des Iapetos, der von den Menschen alle durch seinen ungeheuren Körper überragte. Die äußerste Erde und die hohe See unterstand diesem König, der den keuchenden Pferden Sols Wasser darbringt und die abgenutzten Wagenachsen aufnimmt.‘

122 Zur Widerlegung mancher Deutungen, die damit argumentieren, dass kein Anachronismus vorliegen kann, weil Ovid zwei verschiedene Atlanten meine, s. Tronchet 1998, 372f. und Wheeler 1999a, 133f. Allerdings zeichnet die Darbietung an sich schon ein eindeutiges Bild.

123 Letzteres wird durch die beiden präsentischen Verben in seinem gegenwärtig andauernden, weil täglich aufs Neue stattfindenden Vollzug präsentiert, wobei auch erat (633) diesen Aspekt gegenüber dem eher komplexiven fuit (632) ausdrückt. Vgl. zu den einzelnen Details Bömer ${ }^{2} 2011$ und Barchiesi/ Rosati 2007, ad loc.

124 Oder als Frage formuliert: „Have we forgotten that in 2.296 Atlas already supported the axle of the sky?“ (Anderson 1997, ad loc.). 
In der weiteren Interaktion mit Perseus ist Atlas dann in einer für Ovid keineswegs typischen Art und Weise auffallend häufig explizit beim Namen erwähnt (644, 646, 653, 657), ohne dass dies über Antonomasien oder Umschreibungen variiert wird. ${ }^{125}$ Dadurch wird auch hier das diegetische Geschehen in eine möglichst präzise, unzweideutige Relation zu der damit bezeichneten Figur gesetzt. ${ }^{126}$ Wichtig ist, dass Ovid den Eigennamen das letzte Mal an einem für die Erzähllogik bedeutsamen Punkt setzt, beim Aition für eine fiktiv-reale wie auch reale Erscheinung:

quantus erat, mons factus Atlas. ${ }^{127}$

Zusammen mit dessen quantitativen Ausmaßen, die in Vers 631 als das erste Charakteristikum vorgebracht werden, ist er hier eindeutig als derjenige identifizierbar, auf den Perseus nach seiner Flugreise gestoßen ist. Die nachfolgende Metamorphose, die im factus (657) schon abgeschlossen scheint, wird dann mit nam (ebd.) kausal verbunden und in aller Lebendigkeit dargebracht, sodass am Ende klar ist, warum ,der ganze Himmel auf jenem ruhte' (omne ... caelum requievit in illo - 661f.).

Wie daher zwei der namentlichen Nennungen - die in 657 sowie die bei der parenthetischen rhetorischen Frage kurz vorher: quis enim par esset Atlantis/ viribus? - ${ }^{128}$ den Anachronismus zum Atlas während des großen Feuers zu verfestigen scheinen, kann dies in ähnlicher Weise bei den anderen beiden Fällen hinsichtlich des zweiten und dritten Anachronismus beobachtet werden. Als nämlich Perseus sich ihm als Jupiter-Sohn vorstellt, ${ }^{129}$ erinnert er sich an folgenden, in der diegetischen Jetzt-Zeit ,alten Orakelspruch' (vetusta sors - met. 642f.):

,tempus, Atlas, veniet, tua quo spoliabitur auro arbor, et hunc praedae titulum Iove natus habebit." [645] id metuens solidis pomaria clauserat Atlas moenibus [.....$^{130}$

Die zusätzliche vergangene Zeitebene, die als Plusquamperfekt auch im Verbtempus bei clauserat (646) zum Ausdruck gebracht ist, validiert die fiktive Gegenwart als solche - und damit auch den ersten Anachronismus -, während die Prophezeiung auch eine mit einer gewissen Erwartung verbundene Perspektive in eine zum Augenblick ihrer Äußerung noch unvollendete Zukunft ermöglicht. Denn Atlas als an-

125 Ein ähnlicher Fall, bei dem ebenso bzw. noch viel mehr die Etymologie als Prinzip bedeutsam ist, findet sich bei Kyknos im zwölften Buch. S. dazu Geitner (im Erscheinen).

126 Der Eigenname ist dazu das Mittel der Wahl. S. dazu u. Kap. 7.1.3.3a.

127 Met. IV, 657: ,Groß wie er war, wurde Atlas zum Berg.

128 Met. IV, 653: ,Wer nämlich könnte den Kräften des Atlas ebenbürtig sein?`

129 So in met. IV, 640: generis mihi Iupiter auctor (,Urheber meines Geschlechts ist Jupiter').

130 Met. IV, 644-647: ,,Eine Zeit wird kommen, Atlas, in der dein Baum seines Goldes beraubt werden wird, und ein Sohn Jupiters wird sich um diese Beute einen Ehrentitel erwerben. ‘ Dies fürchtend hatte Atlas seine Obstgärten mit starken Mauern eingeschlossen. 
gesprochener Adressat und Atlas als derjenige, der aus der Weissagung Konsequenzen gezogen hat, sind identisch. Mit der Anwesenheit des als Jupiter-Abkömmling ausgewiesenen Perseus scheinen folglich die verheißenen Umstände nun eingetreten zu sein und ein gewisser Moment der Entscheidung anzustehen. Da aber der Grund für Perseus' Aufenthalt in Ovids Version allein in seinem wohl ohne Täuschungsabsicht geäußerten Gesuch um gastliche Aufnahme liegt - hospitium requiemque peto (,Gastfreundschaft und Ruhe suche ich ${ }^{*}$ 642) -, ist in der Entschiedenheit von Atlas' Zurückweisung die Möglichkeit zum Irrtum schon angedeutet. ${ }^{131}$ Dessen Versteinerung im Anschluss gibt dem im Orakel liegenden warnenden Ton Recht, so als habe er sich tatsächlich vor einem Abkömmling Jupiters schützen müssen; indes wird auf den nur schemenhaft bezeichneten Aspekt mit dem Baum, dem Gold (644f.) und jenem praedae titulus (645) in keiner Form weiter eingegangen. Der Anblick der Medusa, den Perseus ihm zur Entgegnung als Gastgeschenk (munus - 655) gewährt, erübrigt es dann scheinbar endgültig, sich weiter damit auseinandersetzen.

Ein Zweifel an der Wahrhaftigkeit von sprachlichen Äußerungen, die bereits im Vorwurf gegenüber Perseus, dass er den Ruhm seiner Taten erlüge (gloria rerum/ quam mentiris - 649f.), thematisiert wird, rückt später nochmals in den Vordergrund, wenn Perseus vermeintlich selbst auf seine Taten zu sprechen kommt. Als dieser nämlich am Hof der Kephenen aufgefordert wird, zu berichten, wie er in den Besitz des Medusenhaupts gelangt sei, schließt Ovid dies folgendermaßen an:

narrat Agenorides gelido sub Atlante iacentem

esse locum solidae tutum munimine molis; ${ }^{132}$

Dass Perseus’ Erzählung, die die letzten rund 30 Verse des vierten Buches ausmacht, zuerst in indirekter und nach ca. zwei Dritteln in direkter Form wiedergegeben wird, dient in erster Linie sicherlich einer Steigerung zum Schluss hin. ${ }^{133}$ Es ist markant, dass im einleitenden Vers, also dort, wo der kommunikative Rahmen definiert wird, neben der indirekten Rede als abgeschwächte Relation zwischen Erzähler und Erzähltem außerdem eine Antonomasie für Perseus steht, die so verrätselt ist, dass de facto lediglich über den Kontext darauf zu schließen ist, dass es sich hierbei um Perseus handelt. ${ }^{134}$ Der offensichtliche Anachronismus, dass es diesen Atlas zu einem

131 Die charakterlichen Ähnlichkeiten des Atlas mit der Unwirtlichkeit und Zivilisationsferne der Polyphem-Figur werden mehrfach herausgestellt bei Barchiesi/Rosati 2007, 331f. Wie Vial 2010, 168, richtig anmerkt, ist es dann zudem noch verwunderlich, dass Atlas in einen Berg und nicht in eine versteinerte Figur wie die Widersacher im Kampf zu Beginn des fünften Buches verwandelt wird.

132 Met. IV, 772f.: ,Der Nachkomme Agenors erzählt, dass es einen unter dem kühlen Atlas liegenden Ort gebe, der durch den Schutz eines festen Massivs gesichert sei.

133 Vgl. Bömer 22011, ad met. IV, 772-803.

134 Nachdem Perseus zuvor über seinen Ur-ur-großvater als Lyncides (767) bezeichnet wurde, ist Agenorides eine doppelte Steigerung, da Agenor entweder nicht einmal selbst der Ur-ur-ur-ur-großvater von Perseus war, sondern lediglich der Bruder von demjenigen, der diesen Verwandtschaftsgrad tatsächlich hatte: Belos (s. dazu die Tabelle bei ebd., 188); oder aber er ist nach einer alternativ bezeugten 
Zeitpunkt noch nicht gegeben haben kann, als er sich durch die Enthauptung der Medusa ein Instrument verschaffte, mit dem er unter seiner namentlichen Nennung als Medusae ... squalentia ... ora (,das verworrene Antlitz der Medusa' - met. IV, 655 f.) Atlas' Versteinerung verursacht, steht also keineswegs allein. ${ }^{135}$

Diese drei Phänomene zusammengenommen rücken wieder einmal das problematische Verhältnis von Erzählerwissen und sozusagen diegetischem Weltwissen ins Bewusstsein und stellen erneut in witziger Provokation das leserseitige Vertrauen in die vermittelnde Instanz und die Bedeutung, die es konstruiert, auf die Probe. ${ }^{136}$ Denn weder erzählt Perseus wegen seiner spezifischen Abstammung diese Geschichte, sodass Agenorides (772) im konkreten Kontext nicht nur eine unzureichende, sondern auch eine sachfremde Zuschreibung von Seiten des Primärerzählers ist; noch stammt die Information gelido sub Atlante (ebd.) vom intradiegetischen Erzähler Perseus, womit auch dieses Detail, da es syntaktisch in zweifacher innerer Abhängigkeit - über iacentem (ebd.) einerseits und narrat (ebd.) andererseits - steht, von einem wahrheitsgemäßen Haupterzähler eigentlich nicht zugelassen hätte werden dürfen.

In einer noch pointierteren Form ist dies am Ende der indirekten Rede noch einmal in Szene gesetzt und stellt so einen gewissen Rahmen zu jener unzuverlässigen Einleitung her:

addidit et longi non falsa pericula cursus, quae freta, quas terras sub se vidisset ab alto, et quae iactatis tetigisset sidera pennis. ${ }^{137}$

Die Doppeldeutigkeit des Verbalvorgangs „hinzufügen“, der sich auf eine rein erzählerische Ebene beziehen kann, aber als ,über die Wahrheit hinausgehen` auch auf den Inhalt selbst, deutet denjenigen Aspekt bereits an, der bei non falsa (787) als verneinte Möglichkeit explizit zum Ausdruck gebracht ist. Ob Perseus dann wirklich all die Meere und Länder erblickt und zudem so genau erkannt hat, sodass er davon

Genealogie (ad Eur. Phoen. 247) ein Sohn des Belos, wodurch er der Bruder von Perseus' Ur-ur-urgroßvater Danaos wäre. Zusätzlich für Verwirrung sorgt noch, dass Kepheus, der baldige Schwiegervater von Perseus und der augenblickliche Gastgeber, wie auch Danaos ein Sohn des Belos und damit entweder Neffe oder Bruder Agenors ist, sodass dieser sogar mit größerer Berechtigung Agenorides genannt werden könnte als Perseus selbst. Aufschlussreich für Ovids Absichten ist der erste Satz im REArtikel zu Agenor: „Ein Herrschername allgemeiner Bedeutung, der es nicht zu mythischer Persönlichkeit, sondern nur zu genealogischer Existenz gebracht hat.“ (Dümmler 1894, 773).

135 Über die bei Atlas singuläre - so Bömer ${ }^{2} 2011$, ad loc - Eigenschaft zum einen, kühl zu sein, die im Gegensatz zu jener vor Hitze glühenden Himmelsachse steht (met. II, 297), und durch die Umkehrung der Verhältnisse zum anderen, dass nun nicht Erde und Meer ,unter diesem (sub hoc - met. IV, 633) sind, sondern der Ort ,unter dem kühlen Atlas“ ist (gelido sub Atlante - met. IV, 772), könnte außerdem eine lose Verknüpfung mit den anderen beiden Anachronismen erkannt werden.

136 Vgl. Wheeler 1999a, 133.

137 Met. IV, 787-789: ,Und er fügte nicht-falsche Gefahren seines langen Flugs hinzu; welche Meere, welche Länder er von der Höhe aus unter sich gesehen und welche Gestirne er durch den Schlag seiner Flügel berührt habe. 
erzählen kann, dürfte angesichts der auffallend deplatzierten Beschreibung von Atlas in überaus zweifelhaftem Licht stehen - und das nicht erst bei der abschließenden Behauptung, er sei durch die Kraft seiner Flügel buchstäblich mit den Sternen in Kontakt gekommen. ${ }^{138}$

Eine weitere Zäsur im Narrativ über Atlas, die auch die Wahrhaftigkeit von Perseus' Taten betrifft, gibt es im neunten Buch, da sich dort mit Herakles just derjenige Jupiter-Sohn zu Wort meldet, vor dem Atlas eigentlich in der Prophezeiung in met. IV, 644f. gewarnt wurde. ${ }^{139}$ Als Abschluss seines vollständig und „more rhetorico“ ${ }^{140}$ dargelegten Tatenkatalogs bringt nämlich der unter Sterbensqualen leidende Heros als letzten Punkt an, er ,habe mit diesem Nacken den Himmel getragen' (hac caelum cervice tuli - met. IX, 198). Da Perseus aber offenbar der erste und wohl auch letzte Jupiter-Nachkomme war, mit dem Atlas zu tun hatte, weil nach diesem Zusammentreffen nur mehr ein mons Atlas (met. IV, 657) übrig war, erweist sich die sehr implizit gehaltene Äußerung des Herakles als ein Anachronismus. ${ }^{141}$

Ähnlich wie beim intradiegetischen Erzähler Perseus stellt sich daher auch hier die Frage, ob die Aussage des intradiegetischen Sprechers Herakles wahr sein kann. $\mathrm{Zu}$ verifizieren wäre dies nur vor dem Hintergrund eines von Ovid vermittelten Berichts - mit der Schwierigkeit aber, dass dieser sich selbst bereits als widersprüchlich gegenüber einer früheren intradiegetischen Figur (Tellus) erwiesen hat. Um diesen impliziten Rückverweis auf Atlas bei Herakles’ Tod deutlich vor Augen zu führen, ist dies mit jener Schlusspointe nach der Verstirnung des Herakles (sensit Atlas pondus met. IX, 273) unmissverständlich, weil namentlich, kenntlich gemacht. Der besondere Witz an diesem Ausdruck ist es, dass damit Atlas eindeutig identifizierbar, aber nicht definitiv festlegbar ist: Offen bleibt, ob im eigentlichen Sinn eine anthropomorphe Figur oder in der uneigentlichen, die dichterische Lizenz ausnutzenden Bedeutung, das Atlas-Gebirge gemeint ist. ${ }^{142}$

Klarer dürfte allerdings sein, auf wessen Schultern sich Pythagoras dann während seines geistigen Streifzugs stellt. Er fasst dabei unter anderem den Entschluss (iuvat met. XV, 148), ,auf einer Wolke dahinzufliegen und auf den Schultern des rüstigen Atlas Halt zu machen' (nube vehi validique umeris insistere Atlantis - met. XV, 149). Wie die Vorstellung der gedanklichen Reise selbst so ist auch das Bild des Atlas eine

138 Vgl. Wheeler 1999a, $133 \mathrm{f}$.

139 Vgl. ebd., $134 \mathrm{f}$.

140 Bömer 1977, 329.

141 Denn entweder hätte nach Perseus' Aufenthalt noch ein Atlas in Menschenform existieren müssen, sodass dieser dem Herakles als Entschädigung für das Stemmen des Himmelsgewölbes jene goldenen Äpfel der Hesperiden besorgen kann; oder aber Herakles hätte seinem Urgroßvater Perseus zuvorkommen müssen, was aber sowohl genealogisch als auch aufgrund der erzähllogischen Motivation des Geschehens in met. IV, 642-662 als widersprüchlich erscheint.

142 So stark sie auch sein mag, so eindeutig, wie es Wheeler 1999a, 134, sieht, ist die Referenz auf den anthropomorphen Atlas in letzter Konsequenz aber nicht. Gerade in seiner Doppeldeutigkeit besteht doch der Reiz dieser Bezeichnung und eine solche Ambiguität findet sich nicht zuletzt schon bei mons factus Atlas. Vgl. dazu Vial 2010, 169. 
Metapher, derer sich nicht zufällig ein Sprecher bedient, dessen Stimme gemeinhin als die des Dichters angesehen wird. ${ }^{143}$ Auf diese Weise bestätigt sich noch bei der letzten Nennung dieses mythologisch-geographischen Phänomens, dass das einzig verlässliche Prinzip in der Auseinandersetzung damit eine zwar unzuverlässige, aber dafür umso attraktivere Dichtersprache ist.

Im Ganzen betrachtet hat jeder intradiegetische Sprecher seine ganz eigene Vorstellung von Atlas, die stets vor allem der eigenen Redeabsicht entspricht: Tellus möchte mit der Dimension ihres Leids Jupiter zum Handeln bewegen, Perseus - so er denn selbst spricht - die Aufmerksamkeit auf die Exotik des Ortes lenken, Herakles die Monumentalität seiner Tat in einen Kontrast zum gegenwärtigen Leid setzen und Pythagoras den uneingeschränkten Horizont seines Denkens unterstreichen. In allen Fällen schlägt es aber fehl, Atlas als eine reale Erscheinung zu deuten, weil er selbst entweder eine nicht-reale Figur mit unrealistischen Eigenschaften ist oder aber seine Existenz unrealistisch ist. Er bleibt sozusagen Metapher oder wird erzählerisch über uneigentliches Sprechen auf diesen Sinn zurückgedrängt. ${ }^{144}$

Was im Kleinen jeder Sprecher für sich macht, entspricht letztlich der Gestaltungsabsicht des Erzählers im Großen, der anhand dieser Figur eine metapoetische Lesart herauszufordern scheint. Seine geistreich-humorvolle Ästhetik macht in ihrer entschiedenen Priorisierung auch nicht vor einer Figur halt, die in ihrer ideologischen Überhöhung als Symbol der Stabilität und Sicherheit gedeutet wird. ${ }^{145}$ Als poetisch unverbindlicher Gegenentwurf verliert dieses Deutungsangebot weder in Anbetracht der stoffinhärenten Unvereinbarkeit jeglicher Details an Überzeugungskraft - dafür ist der Widerspruch allzu ostentativ in Szene gesetzt - noch unterliegt es dadurch der Obligation, für eine außerdiegetische Realität letztbegründend zu sein und ihr sozusagen stabile Bedeutungsträger zur Verfügung zu stellen. ${ }^{146}$

\subsubsection{Anachronistische Grenzgänger}

In den „Metamorphosen“ wird in nahezu jeder Einzelgeschichte mindestens ein neuer, zum Teil auch mehrere neue Bedeutungszusammenhänge geschaffen und implizit durch die innere Abfolge und logische Verknüpfung in einem Zeitraster verankert. Die meisten fiktiven Objekte jedoch, die in der fiktiv-diegetischen Welt entstanden sind und eine Identität mit dem entsprechenden realen Objekt behaupten, sind aber entweder so speziell, dass sie im weiteren Verlauf der Erzählung entweder

143 Vgl. Bömer 1986, $269 \mathrm{f}$.

144 Deshalb ist es kein Widerspruch, sondern vielmehr ein überzeugender Beweis für eine solche Deutung, dass er für die Welt des Mythos, also für die Welt einer uneigentlichen Weltdeutung als verlässlicher genealogischer Ankerpunkt (für Merkur und Hermaphrodit) genutzt wird. In diesem Bereich kann schließlich seine Existenz volle Gültigkeit beanspruchen.

145 Vgl. Wheeler 1999a, 135 und Hardie 2015, ad met. XV, 147-151.

146 S. dazu die weiteren Überlegungen im Kontext der Aktualisierung u. Kap. 7.2.1. 
nicht mehr oder dann der zeitlogischen Determination entsprechend vorkommen; ${ }^{147}$ oder aber sie sind so allgemein, dass die Veränderung, die durch eine Metamorphose in der fiktiven Welt verursacht wird, wenig Konfliktpotenzial gegenüber früheren und späteren Geschichten aufweist. ${ }^{148}$ Die darin liegende Implikation ist für sich plausibel und fordert nicht dazu auf, hinterfragt zu werden.

Es gibt aber Grenzfälle, in denen Ovid die Erwartung, dass es mit dieser Behauptung und ihrer zeitlichen Verortung schon seine Richtigkeit haben wird, mit Nachdruck aufbaut, um sie im Anschluss in irgendeiner Form wieder als unzutreffend zu erweisen.

Für diesen Effekt ist auch bedeutsam, dass in vielen Fällen in den „Metamorphosen“ die fiktive Historizität eines Ereignisses explizit herausgestellt wird. Beispielsweise geschieht dies vor der Daphne-Geschichte, eine der ersten größeren Einzelepisoden des Gedichts. Dort heißt es: ,Es gab noch keinen Lorbeer (nondum laurus erat - met. I, 450), weshalb sich die Gewinner bei den Pythien in diesem Damals mit einem anderen Geäst schmücken mussten. Zwar ist dieses nondum hier nur auf ein einziges Objekt bezogen und nicht schlechthin übertragbar auf andere Fälle, eine gewisse Deutlich- und wohl auch Vorbildhaftigkeit für den weiteren Verlauf der Gesamterzählung, wonach das Resultat einer jeden Verwandlung eine Novität in der fiktiven Welt darstellt, hat dies aber allemal. Da diese Form der zeitlichen Verankerung immer wieder und über das gesamte Gedicht hinweg auftaucht, verliert auch die zeitliche Implikation - so unverbindlich sie für andere Metamorphosen auch sein mag - nie ganz ihren Stellenwert für die grundsätzliche Wahrnehmung der Erzähleraussagen. ${ }^{149}$

In drei Fällen ${ }^{150}$ tangiert das bzw. überschreitet das die Grenze zum Anachronismus. Die Grundsituation ist immer die, dass der Haupterzähler aus seiner epistemischen Privilegierung heraus für die sprachliche Beschreibung der fiktiven Welt auf Begriffe zurückgreift, die dort in Folge einer Metamorphose erst noch entstehen werden. Ob ein Anachronismus vorliegt oder nicht, hängt letztlich davon ab, wie eindeutig der bezeichnete Vorgang oder Gegenstand als Zustand in dieser Welt behauptet ist bzw. wie eindeutig er aus dieser Welt herausgehalten und dem Sprecher und seinem Standpunkt zugeschrieben werden kann. ${ }^{151}$

147 Etwa eine singuläre Erscheinung wie der Battos-Felsen in Arkadien (met. II, 705-707).

148 Beispielsweise, wenn die Minyas-Töchter in Fledermäuse verwandelt werden (met. IV, 407-415).

149 Zur besonderen Problematik dieser Zeitadverbien bei den Epitheta ornantia s.u. Kap. 6.2.1.2.

150 Möglicherweise existieren aber noch weitere, bislang schlicht unbeachtete Fälle.

151 Dass Ovid nicht wenig Aufwand betreibt, um allein gegen die Möglichkeit der klaren Grenzziehung zu opponieren, muss an einem solchen Punkt in dieser Arbeit nur mehr der Vollständigkeit halber hinzugesetzt werden. Beinahe emblematisch ist dies in met. IV, 772 und an der Atlas-Figur im Allgemeinen verwirklicht. S. dazu o. Kap. 5.1.2.4. 


\section{a) Merkurs Zirkelflug (met. II, 721)}

Ein an sich klarer, aber gerade wegen seiner sprachlichen Expressivität bemerkenswerter Fall ist es, dass Ovid im zweiten Buch bei der an späterer Stelle noch zu betrachtenden Akropolis-Szene Merkur dabei beschreibt, wie er ,seine Flugbahn einlenkt‘ (inclinat cursus - met. II, 721) und ,die gleichen Lüfte bezirkelt‘ (easdem circinat auras - ebd.). ${ }^{152}$ Das Verb circinare ist in lateinischer Dichtung so ungewöhnlich wie die deutsche Übersetzung, meint aber genau diesen technisch präzisen Vorgang. ${ }^{153}$ Der besondere, wohl auch intendierte Witz daran ist, dass Merkurs Rundflug just an einem sehr deutlich als athenische Akropolis ausgewiesenen (festas in Pallados arces - 712; super Actaeas ... arces - 720) Ort stattfindet. Denn dieser wird sich in den „Metamorphosen“ noch als Geburtsstätte des Zirkels erweisen: Ehe Daidalos seinen Schüler Perdix kopfüber, von der heiligen Feste der Minerva' (sacraque ex arce Minervae - met. VIII, 250) hinabwirft, erfindet dieser dort neben der Säge ein Gerät, das mit beinahe kindlicher Neugier beschrieben wird:

primus et ex uno duo ferrea bracchia nodo

vinxit ut aequali spatio distantibus illis

altera pars staret, pars altera duceret orbem. ${ }^{154}$

Mit primus (247) ist zweifellos Perdix als der Erfinder des Zirkels im Sinne des typisch

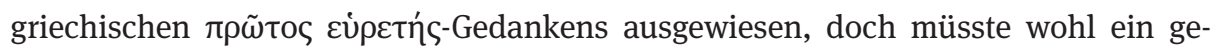
wisser Anteil an dieser Leistung auch dem Genius Loci zuerkannt werden. Anders nämlich als Perdix, dessen (Aus-)Gleiten eine Lüge ist - lapsum mentitus $-{ }^{155}$ und der auch als Vogel in Erinnerung an den Sturz nur ,nahe am Boden fliegt' (propter humum volitat - 258) und ,die Höhen fürchtet' (metuit sublimia - 259) - konnte nämlich der fliegende Merkur die Stadt vorher schon von der Höhe aus einzirkeln.

Ein Anachronismus liegt aber nicht vor, weil für die Beschreibung von Merkurs Flug die Existenz des fiktiven Objekts „Zirkel“ nicht erforderlich ist und das sprachliche Konzept klar aus dem extradiegetischen Wissensbereich stammt. ${ }^{156}$

152 Zur Stelle s.u. Kap. 6.3. Vgl. auch Bömer 1969, ad loc.

153 Dieser ist außerdem im direkten Kontext nicht nur von einem Gleichnis eingeleitet, das seinen Bildbereich in einer aus dem römischen Alltag vertrauten Szene hat, sondern mit weiteren, in der Dichtersprache vor Ovid ungebräuchlichen Wendungen umrahmt. Vgl. Geitner 2019, 129f., wenn auch die dortige Übersetzung als Gleichnis (d. h. ,wie ein Zirkel') die eigentliche Problematik umgeht.

154 Met. VIII, 247-249: ,Auch hat er als Erster zwei eiserne Arme an einer Verbindung befestigt, sodass der eine Teil, wenn jene bei gleicher Entfernung auseinanderstehen, steht, der andere Teil einen Kreis zieht.'

155 Met. VIII, 251: ,Er [sc. Daidalos] hatte vorgegeben, dass er [sc. Perdix] ausgerutscht sei‘. Lateinisch labi meint sowohl das ,Ausgleiten“ im Sinn eines Lapsus als auch das, Gleiten“ durch die Lüfte.

156 Dass Perdix im allgemeinen eine wichtige rückweisende Funktion im Aufbau der Daidalos-Episode hat, wird grundsätzlich diskutiert bei Tsitsiou-Chelidoni 2003, 140-142. 


\section{b) Der anonyme Vogelreichtum des Kaystros (met. II, 252 f.)}

Wohl exakt an der Grenze zwischen fiktiver Realität und fiktionaler Zuschreibung und damit im Graubereich zwischen einer anachronistischen und zeitlich richtigen Erzähleraussage ist die Schilderung des in der Antike für seinen Schwanenreichtum bekannten Kaystros. Im Flusskatalog bei jenem von Phaethon ausgelösten Weltenbrand heißt es über ihn:

et quae Maeonias celebrabant carmine ripas

flumineae volucres medio caluere Caystro. ${ }^{157}$

Betrachtet man diese Stelle nur für sich, ist die Namenlosigkeit der Vögel alles andere als befremdlich: Die Paraphrase mittels Relativsatz variiert die bisherige Art der Auflistung und das leicht verrätselte Aufbieten mehrerer Eigenschaften verleiht der Aussage neben ihrem metaliterarischem Anspielungsreichtum durchaus ihren Reiz. ${ }^{158}$ Dass es Schwäne sind, muss dann lediglich implizit ergänzt werden, ist aber für ein Verständnis der Grundaussage nicht einmal erforderlich - als Opfer der enormen Hitze eignete sich jeder beliebige Flussvogel. ${ }^{159}$

Ein tatsächlicher Grund dieser Anonymität erschließt sich allerdings nur wenige hundert Verse später: Phaethons Freund und Verwandter Kyknos wird aus Kummer und Zorn zu einem Schwan und damit zu einem Vogel, den er im Griechischen (кúкvoৎ) und in der lateinischen Entlehnung cycnus im Namen trägt (met. II, 367380).

An sich wäre auch dies keineswegs problematisch, weil, wie bereits festgestellt, weder das erstgenannte Attribut des Kaystros auf diese Metamorphose angewiesen ist noch die individuelle Schwan-Werdung einer fiktiven Figur dem Schwanenreichtum eines Flusses widersprechen muss. Beachtlich an diesem Vorgang ist aber, dass dessen Metamorphose laut Ovid zu einer neuen, vorher nicht existenten Erscheinung führt: fit nova Cycnus avis (,ein neuer Vogel wird Kyknos` - 377). Damit nämlich erfolgt genau die zeitliche Festlegung, die sonst in beiden Fällen nur implizit mitgedacht wird, aber mitnichten sprachlich so determinativ ist, dass sie eine der beiden Eigenschaften zwangsläufig als den Ursprung der anderen ausgibt. ${ }^{160}$ Da der Erzähler aber

157 Met. II, 252f.: ,Und die Flussvögel, die die mäonischen Ufer mit ihrem Gesang bevölkerten, fingen mitten im Kaystros an, Hitze zu spüren.‘

158 Vgl. Anderson 1997 und Barchiesi ${ }^{4} 2013$, ad loc.

159 Bei Homer tummeln sich dort ohnehin neben ,langhalsigen Schwänen` auch Gänse und Kraniche

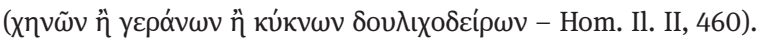

160 Die Argumentation bei Loehr 1996, 165 f. bezüglich der Schwäne ist allein deshalb nicht stichhaltig, weil darin die Erstnennung des Kaystros in met. II, 252f. ebenso wie die von Arachne „erzählte“ Schwanenmetamorphose Jupiters in met. VI, 109 unbeachtet bleiben. Ebenso ist von Loehr die Stelle unberücksichtigt, in der es heißt, dass der dritte Kyknos in einen ,phaethontischen Vogel“ (volucrem ... Phaethontida - met. XII, 581) verwandelt wird. Das ist eine intratextuelle Verknüpfung wie sie klarer nicht sein kann (dagegen ebd., 165: „die einzelnen Metamorphosen mit demselben Ergebnis [werden] 
in der ersten Stelle den Namen der Vögel nicht expliziert und als solchen erst mit Kyknos gewissermaßen einführt, ist der Anachronismus in letzter Konsequenz verhindert.

Anhand dieses „Flirts mit der Möglichkeit eines ,Fehlers““161 legt Ovid aber genau den Überschneidungsbereich eines fiktiven Seins und einer erzählerischen Notwendigkeit offen, dieses Sein mit spezifischen und oftmals auf konventionelle Vorstellungen zurückgehenden Begriffen bezeichnen zu müssen. In diesem Sinne passt es auch sehr gut ins Bild, dass an einer späteren Stelle, wo also jene nova avis schon ,in der Welt“ ist, auch über den Kaystros gesagt werden kann: carmina cycnorum labentibus audit in undis. ${ }^{162}$ Als wollte Ovid damit augenzwinkernd unter Beweis stellen, dass in seiner Erzählung - bzw. der der hypodiegetischen Erzählerin Kalliope - alles seine zeitliche Richtigkeit habe.

\section{c) Ritus und Religiosität (met. XV, 483)}

Göttlich-menschliche Interaktion ist ohne Zweifel ein Wesensbestandteil der „Metamorphosen“. Deshalb ist es von Beginn an notwendig, ein spezifisches und in Ovids Streben nach Anschaulichkeit sehr konkretes Verhalten vor allem der Menschen gegenüber Göttern zur Darstellung zu bringen. Bereits im Allgemeinen knüpfen sowohl

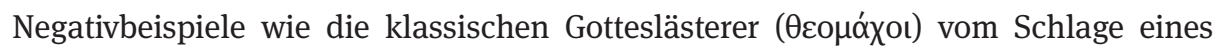
Lykaon als auch Vorbilder an Frömmigkeit wie Deukalion und Pyrrha an solche Vorstellungen von Religiosität an. ${ }^{163}$

Ein konkreter Vollzug von Sakralhandlungen, wie er neben vielen anderen Fällen für das letztgenannte Paar dann in met. I, 371-383 sehr bildhaft und unter Verwendung einiger markant unzeitgemäßer Eigenschaften geschildert wird, kann deshalb nur mithilfe von Aktualisierungen erzählt werden. ${ }^{164}$ Weil es sich dabei um eine nichthistorische Implikation eines zeitlichen Zustandes - nebenbei bemerkt ein Zustand,

gar nicht erst zueinander in Beziehung gesetzt.“).Vgl. dazu O’Hara 2007, 125; Papaioannou 2007, 83-86 und Vial 2010, 84.

Eine genauere, über das hier verhandelte Thema hinausreichende Studie zu den Schwänen in den „Metamorphosen“ findet sich an anderer Stelle (s. dazu Geitner (im Erscheinen)).

161 So (wortgetreu übersetzt) Keith 1992, 139. Bei Bömer ist es in Gleichsetzung von fiktiver und realer Wirklichkeit ein „poetischer ,Anachronismus““ (Bömer 1969, ad met. II, 377).

162 Met. V, 387: ,die Lieder der Schwäne in den dahingleitenden Wogen hört er.

163 Auch erzählerisch wird das eindeutig ausgedrückt: Zu Ersterem heißt es, ,Lykaon verlacht die frommen Gelübde‘ (inridet ... pia vota Lycaon - met. I, 221); und Letztere sind folgendermaßen charakterisiert: non illo melior quisquam nec amantior aequi/ vir fuit aut illa metuentior ulla deorum (,nicht gab es irgendeinen Mann von besserem und gerechtigkeitsliebenderem Sinn als jenen oder irgendeine Gottesfürchtigere als jene - met. I, 322f.) oder schlicht cultores numinis (,Verehrer göttlichen Waltens - met. I, 327).

164 Und dies gilt nicht nur für einzelne Details, die sich wie z.B. beim mehrfach vorkommenden Weihrauch-Opfer, wo Bömer in den meisten Fällen auf einen Anachronismus aufmerksam macht (vgl. u. a. Bömer 1977, ad met. VIII, 277-280), in einer historischen Dimension erfassen lassen. 
der für eine Realität zur Zeit von Deukalion und Pyrrha ohnehin nicht historisch erzählt werden kann - handelt, ist diese als solche nicht anachronistisch, zumindest bis zur Hälfte des 15. Buches.

Dort nämlich bringt Ovid in der Tat noch eine Aitiologie für den römischen Ritus vor, wenn er über den nun als Regent des ,latialischen Volkes' (populi Latialis - met. XV, 481) eingesetzten Numa erzählt: ,Er hat sie in den opferbezogenen Gebräuchen unterrichtet' (sacrificos docuit ritus - 483). ${ }^{165}$ Weder aber wird ein direkter Adressat dieses Unterrichts noch sein konkreter Inhalt genannt, vage ist außerdem der Bezug zu Rom. ${ }^{166}$ Verglichen mit der Verbindlichkeit einer mit primus oder novus markierten Aussage wie z. B. bei Perdix bzw. Kyknos, ist die hier vorliegende Assertion hinsichtlich der fiktiven Realität eher schwach. ${ }^{167}$ Gleichermaßen ist dadurch kaum die Schlussfolgerung zulässig, dass andere Kulturen nicht auch ihre rituellen Praktiken gehabt haben, auch wenn sie in den „Metamorphosen“ merkwürdigerweise sehr gleich aussehen, und alle zuvor so lebhaft praktizierten Rituale nicht auch existiert haben können. ${ }^{168}$

Grundsätzlich könnte daher von einem Anachronismus gesprochen werden; weil aber einerseits die Vielzahl an Behauptungen, die eine Religiosität vorher affirmieren, ${ }^{169}$ Aktualisierungen sind und daher nur bedingt einen eigentlichen Zustand beschreiben und andererseits die hierzu im Widerspruch stehende Aussage über die sacrificos ... ritus (met. XV, 483) in mehrfacher Hinsicht unspezifisch ist, sollte dieser Anachronismus wohl besser lediglich zur Kenntnis genommen, aber nicht in seiner Merkmalhaftigkeit überbewertet werden. ${ }^{170}$

165 S. auch u. Kap. 6.4.4. Erwähnenswert ist noch, dass das Adjektiv sacrificus eine ovidische Innovation ist. Vgl. Bömer 1986, ad loc.

166 Gewissermaßen als Apo koinu steht unmittelbar im Anschluss gentemque (483), aber auch dieses ,Volk' wird nur allgemein als ein kriegerisches beschrieben.

167 S. zu solchen aitiologisch-temporalen Markern Myers 1994, 63-67.

168 Hierzu müssten nicht nur alle Aktualisierungen als spezifisch römische Kulthandlungen expliziert sein, die in der fiktiven Welt als distinktiv römisch erkannt werden sollen, sodass sie von der Aussage in met. XV, 483 abhängig gemacht werden könnten; sondern auch müsste die überaus allgemeine Implikation, dass Numa die Römer den Ritus gelehrt habe, mit aller Konsequenz und aller Konkretheit auf eine Lebenswelt ausgedehnt werden, die einem hunderte Jahre später lebenden Dichter als gedanklicher Ausgangspunkt für die fiktionale Ausgestaltung seines Mythos gedient hat. 169 Besonders der Umstand, dass die religiöse Praxis wie etwas Selbstverständliches über das ganze Gedicht hinweg dargebracht ist, verleiht den Aktualisierungen eine hohe Plausibilität in Bezug auf die fiktive Realität.

170 In keinem der Gesamtkommentare auch wird met. XV, 483 als anachronistisch angesehen. 


\subsection{Anachronismus in der Hypodiegese - Aktualisierung höherer Stufe}

Der Anachronismus als eine von der Erzählung dekonstruierte Bedeutung bezog sich bei den bisherigen Beispielen stets auf ein fiktives Objekt in Form einer Zuschreibung: Peleus beispielsweise wird als creator Achillis (met.VIII, 309) bezeichnet, obwohl eben dieser Peleus erst später diejenige Aktion vollführt, wegen der er tatsächlich so genannt werden darf: ingentique implet Achille (Objekt dazu ist Thetis; met. XI, 265). Bei den nun zu betrachtenden Fällen hingegen, die so zahlreich sind, dass sie wohl in der Tat ein Sprechen von „numerous anachronisms“171 rechtfertigen können, hat der Verstoß seine Ursache in der Situierung der diegetischen Figur in ihrer konkreten fiktiven Umgebung: Der Primärerzähler Ovid äußert hinsichtlich seines Personals implizite logische Prämissen, welche aber von diesem Personal als in der Diegese handelnde, d. h. insbesondere denkende, sprechende oder wahrnehmende Entitäten offenkundig verletzt werden. Statt der bislang beobachteten passiven Zuschreibung wirken die Figuren daher sozusagen aktiv am Anachronismus mit.

\subsubsection{Grundsätzliches}

Der prototypische Fall ist für eine solche implizite Prämisse der, dass eine Figur als intra- oder hypodiegetischer Sprecher eingesetzt wird. Denn durch die obligatorisch zu setzende Markierung dafür, dass eine direkte Rede erfolgt, ${ }^{172}$ wird zugleich auch der Sprechakt im Hier und Jetzt der Diegese verankert. ${ }^{173}$ In einer subtileren Form liegt dies auch bei der internen Fokalisierung bzw. Innenperspektivierung vor, da der Erzähler das Geschehen aus den Augen bzw. aus dem Kopf der diegetischen Figur heraus betrachtet. Auch dabei befindet sich die Figur in einer zeitlich und örtlich determinierten Umgebung. ${ }^{174}$

Handeln bzw. sprechhandeln diese Figuren dann anders, als es beim vermeintlichen Entwicklungsstand ihrer diegetischen Umwelt - z. B. in met. XIII, wenn Odysseus in der Endphase des trojanischen Krieges vor dem Griechenheer eine Rede hält zu erwarten wäre, erweist sich die von der Erzählung behauptete Situiertheit als unzutreffend oder nur bedingt gültig. ${ }^{175}$ Ein konstitutives Merkmal derartiger Anachro-

171 S. o. S. 105, Anm. 93.

172 In den meisten Fällen erfolgt das durch ein Verbum dicendi (ait, inquit, dicit u.ä.) und wird nach Abschluss der Rede noch einmal zusätzlich herausgestellt.

173 Vgl. Nikolopoulos 2004, 41f. Der zeitliche Aspekt dieser Markierung kann zudem über eine wortoder satzförmige Temporalangabe explizit kenntlich gemacht werden, ist aber ohne Ausnahme immer schon implizit im entsprechenden Verbalvorgang - wegen des finiten Verbs - mitgedacht.

174 Vgl. ebd., 93 und (aus fiktionstheoretischer Sicht) Gutenberg 2000, 152 sowie Surkamp 2002, 162. 175 Deshalb wird dieses Phänomen zuweilen auch unter dem Stichwort „,voice usurpation“ diskutiert, weil der Haupterzähler für seine eindeutig seinem extradiegetischen Standpunkt entstammenden 
nismen ist es, dass sie nur bei all denjenigen fiktiven Entitäten auftreten, die zu aktivem Handeln fähig sind. ${ }^{176}$ Bei den Anachronismen aus Kapitel 5.1 ist das an sich unerheblich. ${ }^{177}$ Weiterhin muss das jeweilige Sprechen und Handeln einer Figur merkmalhaft anders als seine Umgebung sein, was an die definitorische Kernfrage der Aktualisierungen rührt und den Schluss nahelegt, diese inszenierten Anachronismen als Aktualisierung höherer Stufe anzusehen. ${ }^{178}$

Wie noch zu sehen sein wird, mag eine Beurteilung dieser Merkmalhaftigkeit leicht erscheinen, wenn sie von den Extremen aus gedacht wird: Dass der fiktive Pythagoras zu Lebzeiten Numas - an sich bereits ein markanter poetischer Synchronismus - den Untergang einer Stadt nicht kennen darf, der sich erst 373/372 v. Chr. und damit mehrere Jahrhunderte nach Numas wie auch Pythagoras' vermutlichem Ableben ereignet, ${ }^{179}$ ist mit dem nötigen Geschichtswissen leicht feststellbar. Und dass auf der anderen Seite jede Figur in den „Metamorphosen“ auf ein in Hexametern gebundenes Latein zurückgreift - einschließlich konventioneller Metaphern, epischer Gleichnisse und sonstiger Redefiguren -, ist als erzählerische Notwendigkeit ebenso wenig verwunderlich. ${ }^{180}$

Umso schwieriger bzw. letztlich unmöglich ist es, einen objektiven Punkt zu definieren, von dem an eine Äußerung als der jeweiligen Welt und seinem Sprecher signifikant nicht zugehörig angesehen werden muss, weil sie das Maß der konventionell zugestandenen Notwendigkeit überschreitet. Zum einen nämlich kann dies in der Diegese von Kontext zu Kontext verschieden sein: Dass Byblis z.B. im neunten Buch überaus ausführliche Gedanken zur Schriftlichkeit anstellt, ist die logische Konsequenz ihres gänzlich auf Aktualisierungen basierenden Handelns und bestätigt aufgrund der sich dadurch erhöhenden Glaubwürdigkeit viel eher das diegetische Geschehen, als dass es in irgendeiner Weise befremdlich wirkt. ${ }^{181}$ Dagegen reicht in einem eher archaischen Ambiente wohl schon eine einzelne Schreib-Metapher aus, um als signifikant unzeitgemäß aufzufallen. ${ }^{182}$ Zum anderen hängt es zu einem nicht zu vernachlässigenden Teil von der Perspektive des Rezipienten bzw. Interpreten selbst $\mathrm{ab}-\mathrm{d}$. h. seiner individuellen und methodischen Voraussetzungen hinsichtlich des mit einer gewissen Erwartung verbundenen Lektüre- oder Analyseprozesses -,

Gedanken die Stimme der diegetischen Figur ,usurpiert‘. Vgl. Nikolopoulos 2004, 98f. Indes kann es für die „Metamorphosen“ entschieden bezweifelt werden, dass es nur „few occasions“ sind (Nikolopoulos bespricht drei Beispiele) - von der Problematik pauschaler Quantitätsargumente einmal abgesehen. 176 Schon allein daran wird die prinzipielle Ähnlichkeit zu einer Gattung offenbar, die ein Handeln im Namen trägt: Drama. Weiteres dann unten in Kap. 7.2.2.1.

177 Wie gesagt, wird dort den jeweiligen fiktiven Objekten, egal ob leblos oder lebendig, eine Eigenschaft gewissermaßen nur angedichtet.

178 Die genaue sprachlogische Herleitung folgt dann unten bei der Aktualisierung in Kap. 7.1.3.

179 Gemeint ist das von einem Erdbeben und/oder einer Flutwelle zerstörte Helike im Norden der Peloponnes, das Pythagoras in met. XV, 293 erwähnt. Zum Hintergrund s. Bömer 1986, ad loc.

180 S. dazu o. S. 28 f., Anm. 120 und Kap. 7.2.1.2a.

181 S.u. Kap. 7.3.2.2d.

182 S.u. Kap. 7.3.1. 
wieviel Bedeutung der konkreten zeitlichen Situierung von Sprechern und Sprecherinnen beigemessen wird. Von der in der Philologie allgemein dominanten historischen Sicht auf Texte zeugt es, dass diese Anachronismen in den „Metamorphosen“ am häufigsten bei den vermeintlich historischen Figuren in den letzten Büchern detektiert werden, obwohl derselbe Aussagemodus mit derselben Problematik bei ausnahmslos jeder Binnenerzählung vorliegt und mit derselben Argumentation thematisiert werden könnte: So spricht Jupiter z.B., der vor der großen Flut als der erste intradiegetische Erzähler des Gedichts in Erscheinung tritt, von einem Molosser-Volk, das überdies sogar Geiseln entsendet (met. I, 226). ${ }^{183}$

Festzuhalten ist dabei, dass Ovid weder bestrebt ist, die impliziten Prämissen seiner intra- oder hypodiegetischen Erzähler stets aufrechtzuerhalten, noch gezwungen ist, immer gegen sie zu verstoßen. ${ }^{184}$ Für den Fall, dass dies der Lebendigkeit oder Plausibilität des Geschehens oder zuweilen auch einer Erzähler-Ironie in irgendeiner Weise zuträglich ist, wird der Erzählmodus offenbar aufgegeben, der wegen des Fehlens zeitlich merkmalhafter Objekte den Anschein von Historizität wahrt. ${ }^{185}$ Auf diese Weise erfolgt bei der Hypodiegese im Speziellen, was der Haupterzähler in der Haupterzählung im Allgemeinen mittels Aktualisierungen vollzieht: der Gebrauch von Begriffen zur Beschreibung der diegetischen Welt, die zum vermeintlichem $\mathrm{Zu}$ stand dieser Welt nicht vorliegen. ${ }^{186}$ Aus sprachlogischer Sicht setzt sich daher in der Hypodiegese die uneigentliche Erzählhaltung Ovids auf einer anderen narrativen

183 Wohl weil dies so offensichtlich ist, gehen die Kommentare auf die gens Molossa selbst entweder gar nicht ein (Bömer, Anderson) oder nur, um daran etwas in positivistischer Weise zu beschreiben (Barchiesi). Am deutlichsten noch (dem Sinn nach ähnlich auch Lee) ist Haupt ${ }^{11} 1969$, ad loc: „Daß Lykaon von dort einen [sic] Geisel gehabt, scheint willkürliche Erfindung des Ovid.“ Ein Zeit-Aspekt kommt dabei aber nicht zur Sprache.

184 Dies bedeutet in letzter Konsequenz, dass Anachronismen in den Binnenerzählungen an sich kein hinreichender Grund für eine Athetese sind, wie es für met. XV, 426-430 zuweilen noch immer vorgebracht wird: „Hauptgrund für die Athetese ist natürlich der Anachronismus“ (Bömer 1986, 366), was aber noch im selben Satz mit dem Hinweis eingeschränkt wird, dass Ovid davor „sonst keineswegs zurückschreckt“. S. dazu o. S. 100, Anm. 66. Andererseits ist es aber gleichfalls nicht überzeugend, die Anachronismen mit der Chronologie der Gesamterzählung zu legitimieren, wie es u.a. bei Barchiesi 2001, 71-74, unternommen wird. Der logische Verstoß findet ja trotzdem statt.

Ein ähnlicher Fall, in dem eine Konjektur vermutlich zur Vermeidung eines Anachronismus vorgeschlagen wurde (was sich aber nicht durchgesetzt hat), sind die Penates (met. I, 231), von denen Jupiter in der oben erwähnten Rede spricht. Vgl. Bömer 1969, ad loc.

185 S. dazu u. Kap. 7.2.1.2.

186 Wie dies bei Ovid auf der obersten Ebene eine uneigentliche Aussage ist, von der aus nicht auf diesen diegetischen Zustand geschlossen werden kann, so sprechhandeln auch intradiegetische Sprecher auf uneigentliche Weise, wenn sie gleichermaßen dafür auf Begriffe zurückgreifen, die zu „ihrer“ Zeit merkmalhaft unzeitgemäß sind, und ebenso die von diesen wiederum eingesetzten hypodiegetischen Sprecher usw. 
Ebene fort und spiegelt damit auch in dieser Hinsicht die in den „Metamorphosen“ oftmals erkennbare Mise-en-Abyme-Struktur wider. ${ }^{187}$

\subsubsection{Skizze einer Phänomenologie}

Die quasi-historische Verortung einer diegetischen Figur und die Verbindlichkeit, die dieser Implikation beigemessen wird, stellt den einen Faktor dar, von der aus eine Aussage unzeitgemäß erscheint. ${ }^{188}$ Bei einem Sonnengott als einer überzeitlichen und auf das diesbezügliche Wissen notwendigerweise angewiesenen Gestalt fällt es kaum auf, dass seine kosmologischen Aussagen, die er in met. II, 78-83 tätigt, von einer wissenschaftlichen Exaktheit sind, dass sie als „lecture on astronomy“189 bezeichnet werden können. Wenn dagegen der fiktive Odysseus erzählt - er wechselt dafür eigens ins dramatische Präsens -, er schreite nach seinem Überfall auf Rhesos als ein ,Sieger, der sich des Gefangenen bemächtigt und seine Wünsche erlangt hat' (captivo victor votisque potitus - met. XIII, 251), ,auf einem Wagen einher, der die freudigen Triumphe nachahmt“ (ingredior curru laetos imitante triumphos - 252), dürfte er damit für einen Griechen vor Troja allzu sehr wie ein römischer Feldherr denken und sprechen. ${ }^{190}$

Auf der anderen Seite ist aber auch entscheidend, wie spezifisch, d. h. wie eindeutig semantisch festgelegt das vorgebrachte Detail ist. Allgemeine Äußerungen oder solche, die wie bei Sol auf allgemein erfahrbare Erscheinungen referieren, fordern maximal dazu auf, eine Analogie zwischen der fiktiven und der tatsächlichen Wirklichkeit zu erkennen: Etwas ist ähnlich zu einer anderen Sache. Sol hat demgemäß ähnliches Wissen wie ein Astronom. Konkrete Bezeichnungen hingegen verweisen mehr oder minder deutlich auf einen einzigen Sachverhalt: Etwas ist etwas. ${ }^{191}$ Auch wenn der oben erwähnte Odysseus seine Aussage spielerisch abwandelt, tritt die gemeinte Vorstellung deutlich hervor, jene Ist-Beziehung kann sich manifestieren. Aktualisierungen von intra- und hypodiegetischen Erzählern lassen sich deshalb am häufigsten und am eindeutigsten bei denjenigen Ausdrücken feststellen, die am

187 Alles Weitere hierzu dann in Kapitel 7. Von den im Register bei Hardie 2015, 660, aufgeführten „anacronismi“, sind demnach folgende Stellen als Anachronismen in der Hypodiegese, ergo Aktualisierungen anzusehen: met. IV, 122-124 und 176-179; met. V, 341-661; met. VI, 70 - 128; met. VII, 735f.; met. IX, 741-744 und 762; met. X, 160; met. XII, 466; met. XIII, 1- 398 und 251f.; met. XIV, 179-186 und 326-334; met. XV, 287-292; 293-295; 296 und 426-430.

$188 \mathrm{Ob}$ diese Historizität dann aber so absolut gesetzt werden kann, darf entschieden bezweifelt werden, wenn man berücksichtigt, mit welchem Aufwand die Kommunikationssituation zuweilen destabilisiert wird. Ein Paradefall dafür ist Pythagoras. S.u. Kap. 6.4.

189 Loos 2008, 258.

190 Vgl. dazu (mit weiteren Stellen zum Triumph-Motiv in den „Metamorphosen“) Solodow 1988, 82f. Eine witzige Pointe könnte es sein, dass nicht Odysseus einen Triumph nachahmt, sondern lediglich sein Wagen.

191 S. dazu auch u. Kap. 7.1.3.3. Auch dies ist, wie noch zu sehen sein wird, ein Kernaspekt metaphorischen Sprechens. 
definitesten sind: Eigennamen, wie das Beispiel der gens Molossa (met. I, 226) zeigt, und distinktive Bezeichnungen wie z.B. die triumphi (met. XIII, 252). ${ }^{192}$

Allerdings lässt sich auch daraus kein festes Definitionskriterium gewinnen: Eigennamen sind, insbesondere, wenn es sich um geographische Angaben handelt, auf die erzählerische Notwendigkeit zurückzuführen, gewisse Basiskoordinaten für das Handlungsgeschehen abzustecken, sodass auch für sie das grundlegende Problem der Merkmalhaftigkeit bedacht werden muss; ${ }^{193}$ außerdem sind selbst definit scheinende Bezeichnungen mehrdeutig oder in uneigentlicher, $d$. h. metaphorischer oder metonymischer Weise verwendet, wie z. B. das in den „Metamorphosen“ ausnahmslos im poetischen Plural stehende atria. ${ }^{194}$ Auch dadurch ist eine Festlegung auf einen eigentlichen und damit klar als unzeitgemäß aufzufassenden Sinn erschwert.

Und ist schon wegen dieser grundsätzlichen Problematik eine objektive Kategorisierung unmöglich, scheint Ovid als Erzähler diese Ambiguität obendrein noch mit aller Entschiedenheit $\mathrm{zu}$ forcieren. Hierbei sind erstens die eigentlichen Anachronismen zu erwähnen, mit denen das Gemacht-Sein von Bezeichnungen in den Vordergrund gerückt und noch in seiner Fehlerhaftigkeit ästhetisiert wird. Des Weiteren stehen viele Einzelmetamorphosen im Zusammenhang mit einem Namen oder einem namengebenden Prozess, sodass auch für das Verfahren selbst ein Aspekt von Zeitgebundenheit ins Bewusstsein rückt. Dann wird die Namensgebung bei fiktiven Objekten auch in der Binnenerzählung betont - z. B. von der hypodiegetischen Erzählerin Kalliope in met. V, 411 - oder wird sogar vermeintlich authentischen Instanzen seitens intradiegetischer Erzähler zugeschrieben: So setzt Jupiter bei einer Ortsbeschreibung, die er Hermes für seinen nächsten Coup sozusagen auf die Hand gibt, in Parenthese hinzu: indigenae Sidonida nomine dicunt (,die Eingeborenen nennen es [sc. das Land] namentlich das Sidonische` - met. II, 840); ${ }^{195}$ oder an späterer Stelle erzählt ein als ,kalydonischer Fluss' (Calydonius amnis ... adloquitur - met. VIII, 727f.) definierter Sprecher davon, dass der Gipfel eines starren Berges in Skythien Kaukasus genannt wird: Caucason appellant (met. VIII, 798). ${ }^{196}$ Und zuletzt führt nicht nur Ovid selbst die Historizität von namentlichen Nennungen gerade dann ad absurdum, wenn er den Anschein von Geschichtlichkeit erweckt, ${ }^{197}$ sondern auch die diegetischen Erzähler nutzen Namen mit solch expressiven Attributen, dass sie zwangsläufig im Widerspruch zur jeweiligen Realität stehen: So positioniert jene hypodiegetische Sprecherin

192 Zum Problem der „anachronistic names“ im Allgemeinen s. Rood et al. 2020, 71-76.

193 Aber laut Servius ist diese anticipatio über Eigennamen nur ex persona poetae erträglich (tolerabilis), nicht aber, wenn sie per alium erfolgt; dann nämlich ist sie der schlimmste Fehler (vitiosissimus). S. o. S. 60, Anm. 179. Ähnlich auch die Einschätzung von Velleius Paterculus. S.u. S. 271f., Anm. 249.

194 S. dazu u. Kap. 7.1.3.1b.

195 Ähnlich auch bei Venus als hypodiegetischer Erzählerin: indigenae Tamasenum nomine dicunt (,die Eingeborenen nennen es [sc. das Feld] namentlich das Tamasenische“ - met. X, 644).

196 Zweifellos erübrigt es sich bei beiden Sprechern, genauere Überlegungen zur Möglich- oder Unmöglichkeit ihrer Aussage anzustellen.

197 S.u. Kap. 6.2. und Kap. 6.4.1. 
Kalliope einen Teich auf Sizilien ,nicht unweit der Ennaischen Mauern' (haud procul Hennaeis ... moenibus - met. V, 385) und weiß dessen schattenspendenden Baumkranz mit einem Sonnensegel (velum) ${ }^{198} \mathrm{zu}$ vergleichen; außerdem erwähnt beispielsweise Alkithoe, die als dritte Minyade die Geschichte von Hermaphrodit und Salmakis erzählt, dass letztere ihre Haare mit einem ,Kytoriakischen Kamm` (Cytoriaco ... pectine met. IV, 311) ordnet. ${ }^{199}$

In mehrerlei Hinsicht sind demnach die Grenzen zwischen einer merkmallosen und notwendigerweise darzubietenden Ausstaffierung einer fiktiven Welt einerseits und einer zeitlich merkmalhaften und deshalb über die Abgeschlossenheit dieser Welt hinausweisenden Aussage anderseits fließend. ${ }^{200}$ Aus diesem Grund sind die markanten Beispiele - wozu besonders das Rohrbruch-Gleichnis in met. IV, 121-124, die in Olympiaden rechnende Dienerin der Kirke in met. XIV, 324f. und die PythagorasRede wohl als Ganze (met. XV, 75-478) zu zählen sind - wohl nur der sichtbarste Ausdruck dafür, wozu dichterische Sprache prinzipiell fähig ist, deren Primat in der ästhetischen Steigerung der darzustellenden Vorgänge liegt. ${ }^{201}$

\subsubsection{Schlussfolgerungen}

Gewissermaßen als Spitze des Eisbergs repräsentieren diese ausdruckstarken Fälle, die in ihrer Drastik fraglos auch verstörend wirken können, lediglich den an der Oberfläche am leichtesten erkenn- und kategorisierbaren Teil. Die anderen neun Zehntel dieses Phänomens, um die Eisberg-Analogie weiterzuführen, sind dagegen mit abnehmender Stärke des Ausdrucks allenfalls nur bei genauerem Hinsehen als Ähnlichkeits- bzw. Analogiebeziehung sichtbar, verlangen dieses kategorische Erkannt-Werden wohl aber nicht, da ihr Effekt - Anschaulichkeit und Lebendigkeit vortheoretisch ist. ${ }^{202}$

Eine offenkundige Bestätigung findet dies darin, dass nicht nur beide Verfahren das bloß analogisierende sowie das metaphorische - prinzipiell ähnlich sind, ${ }^{203}$ sondern auch in ähnlicher Weise und offenbar zu einem ähnlichen Zweck eingesetzt werden. Wenn in den „Metamorphosen“ diegetische Figuren einen zeitgenössischen Pragmatismus, eine psychologisierende Charakterzeichnung oder eine rhetorische

198 Eine „nationalrömische Institution“ (Bömer ²2011, ad met. V, 389).

199 Das Adjektiv ist vermutlich einschließlich der griechischen Sprache ein Hapaxlegomenon Ovids (auch noch in met. VI, 132) und verdankt sich dem Umstand, dass aus dem von diesem Ort in Kappadokien (entweder Stadt oder Berg) stammenden Buchsbaumholz unter anderem Kämme hergestellt wurden. Vgl. ebd., ad met. IV, 311. Die lateinischen Belegstellen für den/das Kytoros sind bezeichnenderweise Catull, das „Katalepton“ und Vergils „Georgica“.

200 S. auch von Glinski 2012, 153, wo die merkmalhaft unzeitigen Elemente in hypodiegetischen Gleichnissen bezeichnet werden als „reminder of the paper-thin division of real and fictional“.

201 Vgl. von Albrecht 2003, $161 \mathrm{f}$.

202 S.u. Kap. 7.2.1.

203 S.u. Kap. 7.1.2. 
Befähigung offenbaren - für Letzteres sind etwa die Hoplon Krisis in met. XIII sowie die Rechts- und Militärsprache zu erwähnen ${ }^{-204}$, ist dies als allgemeiner Eindruck leicht wahrnehmbar. Will man es aber im Detail, d. h. am sprachlichen Ausdruck selbst erfassen, ist es meist kaum zufriedenstellend zu kategorisieren, weil es in diesen schwer definierbaren Schwellenbereich von Metapher und Analogie fällt. Jupiter beispielsweise schließt seine Rede in der Götterversammlung und damit seinen Entschluss zur Vernichtung der Menschheit mit folgenden Worten ab:

in facinus iurasse putes; dent ocius omnes quas meruere pati (sic stat sententia) poenas. ${ }^{205}$

Durch dent ... poenas und sententia stat, begleitet von Wörtern wie facinus, iurare und merere, erinnert die Diktion als Ganze stark an ein Abschlussplädoyer im forensischen Kontext, sei es im politischen oder im rechtlichen Sinn. ${ }^{206}$ Für sich genommen zeugen die einzelnen Wörter und Junkturen zwar nicht von einer mystischen Ferne, wenn sie in der gleichen Weise, sozusagen prosaisch auch im Alltag eingesetzt werden. Festgelegt sind sie als Begriffe aber auf keinen spezifischen Sachverhalt. Vielmehr lassen sie es durch ihre Allgemeinheit zu, dass neben dem fiktiven Geschehen über eine implizite Wie-Ebene auch ein Vorgang aus der Realität mit- bzw. nebenhergedacht werden kann, ohne dass mit finaler Eindeutigkeit ein direkter Zusammenhang zu dieser außertextlichen Wirklichkeit behauptet werden muss. ${ }^{207}$

An der entscheidenden Grenze zwischen diegetischer und extradiegetischer Welt erweist sich somit schon die Sprache als Erzähler-Medium als indifferent. So unbefriedigend ein solches theoretisches Defizit für eine philologische Studie auf den ersten Blick auch sein mag, mit dem Wissen darum, dass es ein Wesenskern der „Metamorphosen“ ist, die Grenzen von Fiktion und Wirklichkeit, von Nicht-Real und Real sowie von einem vermeintlichen Damals zu einem realen Jetzt beständig und in ansprechender Art und Weise immer wieder neu auf die Probe zu stellen, ${ }^{208}$ darf in diesem Befund umgekehrt sogar der Vorzug erkannt werden, dass dieses Textphänomen mithilfe der Ästhetik eben dieses Textes bestmöglich begründet ist. ${ }^{209}$

204 Vgl. dazu u.a. von Albrecht 1981, 2338-2342 und Solodow 1988, 86-89. Zur Rechtssprache speziell s. Reed 2013, ad met. X, $36 \mathrm{f}$.

205 Met. I, 242f.: ,Man könnte meinen, sie hätten sich zum Verbrechen verschworen; nur recht schnell mögen alle die Buße tun, die zu erleiden - so steht der Entschluss - sie verdient haben.

206 Vgl. Barchiesi ${ }^{4} 2013$, ad loc.

207 Das nämlich ist nicht immer passend, weil es die Plausibilität der fiktiven Szenerie einschränkt. S. auch u. Kap. 7.1.3.1a.

208 Vgl. Kirstein 2019a, 212-214.

209 S. dazu auch u. Kap. 7.2.1. 


\subsection{Zusammenfassung}

Bereits in der fiktionstheoretischen Hinführung hat sich gezeigt, dass ein Sprechen von Anachronismus in Bezug auf fiktionale Texte problematisch ist, weil dabei vorausgesetzt ist, dass die abgebildete fiktive Realität logisch in einer identischen Beziehung zur realen Welt außerhalb des Textes steht. ${ }^{210}$ Wie sich in diesem Kapitel nun herausgestellt hat, ist für eine Kategorisierung der Beispiele in den „Metamorphosen“ auch diese Definition noch zu unscharf, da zwei verschiedene Phänomene darunterfallen: einerseits der Widerspruch zu einem Sinnzusammenhang, den die Erzählung selbst in Bezug auf die Diegese gesetzt hat; andererseits - als ein Spezialfall dieser Setzung - der durch das Sprechen und Denken der diegetischen Figuren verursachte Widerspruch zur implizierten Situierung.

Ihnen beiden gemeinsam ist somit, dass durch sie eine Diskrepanz zwischen der diegetischen Welt und des extradiegetischen Erzählers sichtbar wird, welche sonst in der scheinbaren Objektivität eines epischen Erzählers weitestgehend minimiert ist. ${ }^{211}$ Darüber hinaus jedoch unterscheiden sie sich dadurch, welcher erzählerischen Absicht dies vermutlich jeweils Ausdruck verleihen soll. So zeugt es im einen Fall von einem ohne Übertreibung avantgardistisch zu nennenden Sprachwitz, dass der Erzähler entweder offen provokativ oder spielerisch-elegant das eigene Erzählen ironisiert und dem Leser immer wieder dessen credulitas (am. III, 12, 44) vorhält. ${ }^{212}$ Im anderen Fall, dem der Anachronismen in der Hypodiegese, kann ein solcher „Aha“Effekt durchaus auch eine Rolle spielen, und zwar dann, wenn die Diskrepanz zwischen der fiktiven Szenerie und dem von der Figur geäußerten oder gedachten Sachverhalt so groß ist, dass ein Missverhältnis offen zu Tage tritt. Doch muss dies keineswegs zwangsläufig in einer solchen Deutlichkeit erfolgen.

210 S.o. Kap. 3.3.2.

211 Schon Aristoteles lobt bekanntlich an Homer, dass er in einem sehr geringen Ausmaß von sich selbst bzw. ex sua persona spricht. Vgl. Aristot. poet. 1460a5-8.

212 Vgl. auch die ähnlichen Schlussfolgerungen bei Myers 1994, 93. 